\title{
A state of the art review of hydroforming technology
}

\section{Its applications, research areas, history, and future in manufacturing}

\author{
Colin Bell $^{1}$ (I) $\cdot$ Jonathan Corney $^{1} \cdot$ Nicola Zuelli $^{2} \cdot$ David Savings $^{3}$
}

Received: 13 March 2019 / Accepted: 15 August 2019 / Published online: 18 December 2019

(C) The Author(s) 2019

\begin{abstract}
Hydroforming is a relatively new metal forming process with many advantages over traditional cold forming processes including the ability to create more complicated components with fewer operations. For certain geometries, hydroforming technology permits the creation of parts that are lighter weight, have stiffer properties, are cheaper to produce and can be manufactured from fewer blanks which produces less material waste. This paper provides a detailed survey of the hydroforming literature of both established and emerging processes in a single taxonomy. Recently reported innovations in hydroforming processes (which are incorporated in the taxonomy) are also detailed and classified in terms of "technology readiness level". The paper concludes with a discussion on the future of hydroforming including the current state of the art techniques, the research directions, and the process advantages to make predictions about emerging hydroforming technologies.
\end{abstract}

Keywords Hydroforming · Fluid forming · Cold forming · Sheet Near Net Shape Manufacturing · New manufacturing technologies $\cdot$ Aerospace

\section{Introduction}

Hydroforming is a near net shape metal forming process whereby complicated shapes are created by the utilization of fluid pressure instead of (or in conjunction with) traditional mechanical forces. The hydroforming process has several advantages over other forming processes which has helped establish it in a range of specific applications. These are: the ability to create re-entrant features, reduced thinning [1], enhanced mechanical properties, better surface finish [2], fewer components required in an assembly [3], and less required rework due to the creation of geometries which are closer to the final shape, [4]. These advantages primarily stem from the ability of the working fluid to exert pressure evenly over the entire surface of a material and for the equipment to vary this

Colin Bell

colin.bell@strath.ac.uk

1 Design, Manufacture and Engineering Management, University of Strathclyde, 75 Montrose St, Glasgow G11XJ, UK

2 Advanced Forming Research Centre (AFRC), University of Strathclyde, 85 Inchinnan Drive, Inchinnan PA49LJ, UK

3 Rolls-Royce plc, PO Box 31, Derby DE24 8BJ, UK fluid pressure during the forming cycle based upon an optimized load path.

\section{Hydroforming subcategories}

Hydroforming has been exploited in many manufacturing sectors including the automotive and aerospace industries to produce components which otherwise would be difficult or impossible to form. The fluid pressure allows for more even material expansion and for pressure generation in orientations other than the forming direction which enable creation of additional or more prominent features. Thus, hydroforming fills a manufacturing gap by allowing higher material formability than conventional cold forming [4] with less cost and cycle time as compared to other specialized and nontraditional sheet metal forming technologies like superplastic forming or creep forming, [5]. This increased formability is seen (and quantified by) an increase in the limit draw ratio from 2 with deep drawing to as much as 3.2 with hydroforming [6]. The hydroforming process can be split into three distinct categories: tube, sheet and shell as shown in Fig. 1. This division is based upon the geometry of the blank used during the operation. Each of these three categories are distinct processes that have different key process variables and usually require different equipment. While the 


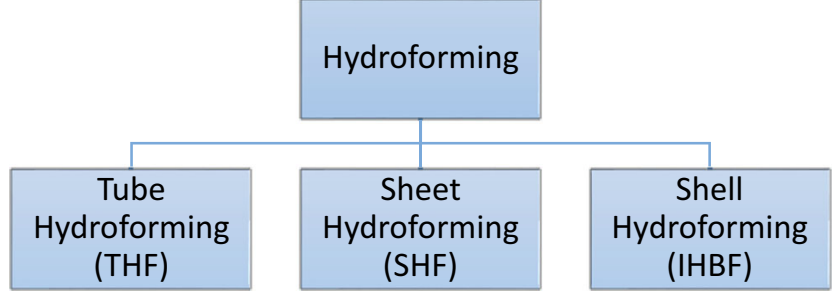

Fig. 1 Top level hydroforming categories; derived from: [4, 6, 8, 9]

advantages and disadvantages will be gone over in detail in "Discussion" section after the process has been fully described, all of these categories utilize the advantages of forming with fluids to produce a more complicated and higher quality final product [3] than traditional pressing processes can provide [2]. An example of how quality can improve with hydroforming is if the increased complexity allowed from the manufacturing process is used to simply design by removing weld lines from fabrications reducing potential weak points in their designs [7].

The tube hydroforming process shown in Fig. 2a:

- Starts with a hollow cylindrical metal tube

- The tube is filled with fluid and expanded to a more complicated geometry

- Often tube hydroforming equipment is fitted with rams which axially feed new material in by pushing on the edges of the tubes during the operation
Fig. 2 Schematic representations of tube, sheet, \& shell hydroforming processes

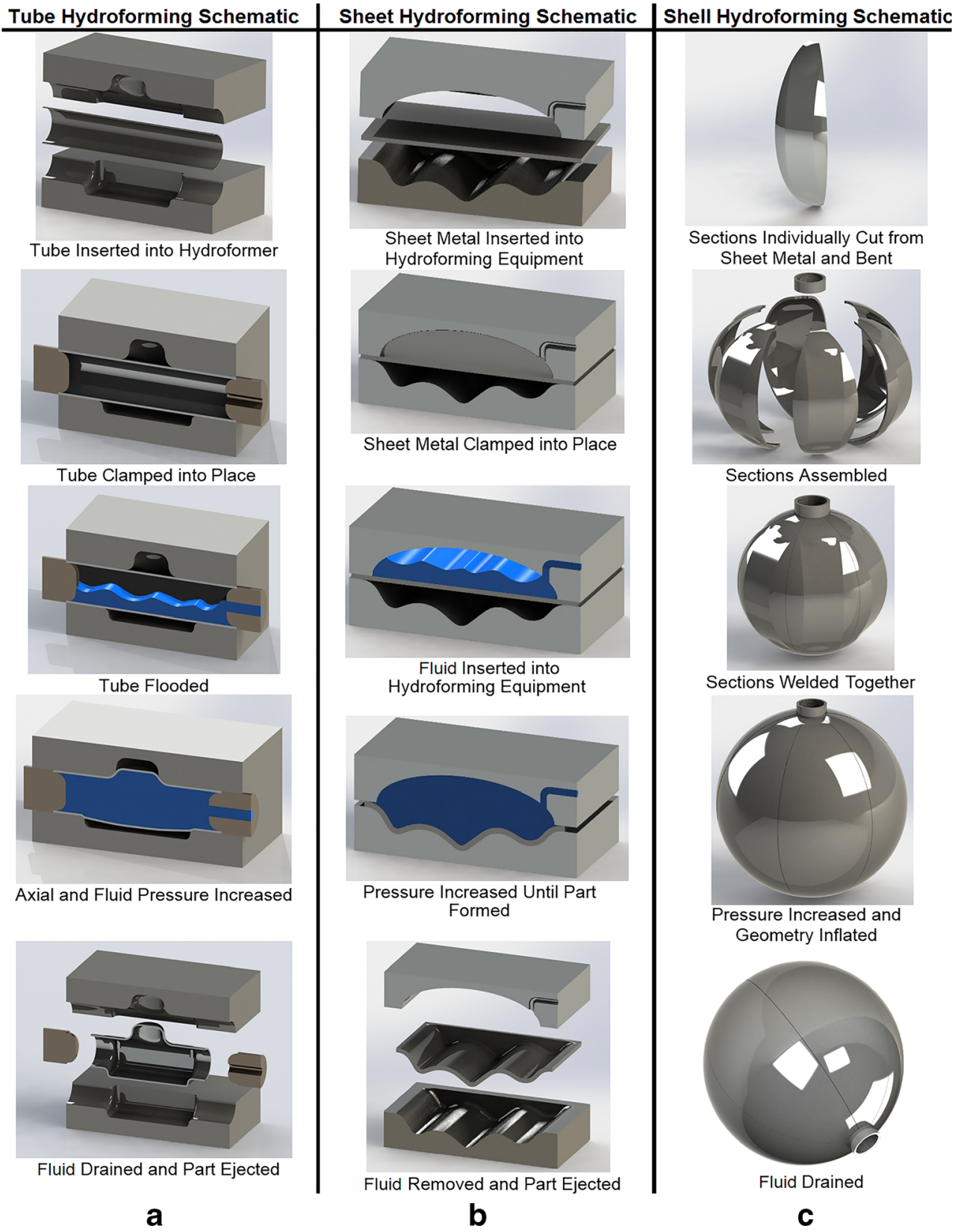


- By simultaneously increasing the fluid pressure on the inside of the tube while feeding new material, axial feeding can reduce material thinning

The sheet hydroforming process shown in Fig. 2b:

- Starts with a sheet metal blank

- Deforms the sheet metal into a final geometry by applying fluid pressure, sometimes in conjunction with mechanical pressure

- The process can either use a male or a female die, these are referred to as a punch or cavity die respectively

- The process bears resemblance to deep drawing, stamping (pressing), and rubber pad forming

Shell hydroforming or "integrated hydro-bulge forming" (IHBF) shown in Fig. 2c:

- Starts with sheet metal blanks each of which is bent into position

- The sheets are then welded into a spherical, oval, or custom hollow shell

- A nozzle is welded on to the exterior

- The interior is filled with fluid which is expanded to bulge the fabricated shape outwards

- Shell hydroforming is a dieless process, meaning expansion takes place in free space and not against a die

There have been a number of recent reviews of each of these categories: for example Koç, et al. 2001 [10] gave an overall review of tube hydroforming technology which included materials and applications. The same author also wrote a dissertation on creating design guidelines for the THF process [11]. In 2003 Harjinder Singh [12] authored a book summarizing sheet and tube hydroforming history and principles of the nineteenth century. Lang, et al. [13] published a review of specific technologies of interest in sheet, tube and shell hydroforming in 2004. Wang. et al. published a review of shell hydroforming technology in 2005 which covered the development of the technology including its applications and information concerning finite element simulations of the process. An edited volume published in 2008 by Koç et al. [6] summarized sheet and tube hydroforming, giving current applications also identified a few research trends such as warm hydroforming and gave an in depth look at the tube and sheet hydroforming process including governing equations. Similarly a tube hydroforming review in 2012 by Alaswad, et al. [2] summarized the recent experiments and literature in tube hydroforming technology. A tube and sheet hydroforming review was written by Lee, et al. who looked into recent technical work and simulations of tube and sheet hydroforming [14].

The aim of this contribution is to: 1 . Provide a comprehensive overview of the state of the art in all forms of hydroforming. 2. Identify emerging hydroforming technologies. 3. Place all the reported systems in a single taxonomy (shown later in Fig. 46) that clearly identify the generic similarities and differences between the processes. 4. Classify the emerging technologies in terms of their technology readiness level (i.e. process maturity). 5. Characterize the position of hydroforming with regard to manufacturing and state the likely future of hydroforming in industry.

\section{Methodology}

Hydroforming literature was included in the analysis if it met one of the following 3 criteria: 1 . Source is a conference or journal publication reporting on a hydroforming or closely related process. 2 . Source has relevant peer reviewed information pertaining to hydroforming or related technology. 3. Because much of the development of hydroforming is commercially driven, sources outside the conventional literature were considered if the source was: a professional, website, or an interview/communication from a known hydroforming component supplier, equipment vendor, or expert. Entries were excluded if they met one of the following 2 exclusion criteria: 1. 1. Source was written in a language other than English. 2. Source did not refer to hydroforming or a closely related technology or field.

The rest of this paper is structured as follows: "Historical context and industrial applications" section summarizes the history and applications of the tube sheet and shell processes and how their applications have changed over time. This is followed by the identification of the key process variables and their importance to the hydroforming process for each category. "Process parameters" section discusses hydroforming techniques which allow for complicated feature generation that are already used in industry. "Materials" section discusses various different metals that have been formed. "Geometry" section discusses geometries including what geometries are possible, basic geometric calculations, and geometries that should be avoided if possible. "Development directions" section discusses the research areas in the different branches of hydroforming including the relative maturity of new hydroforming technologies and the new taxonomy which will help to characterize future hydroforming processes. "Discussion" section discusses the future of hydroforming technology with emphasis on its future in the aerospace sector. And 
finally "Conclusion" section is a conclusion that states how and where the aims were addressed within the text.

\section{Historical context and industrial applications}

\section{Tube hydroforming history}

The first references of tube hydroforming date back to the early 1900s when a patent for an "Apparatus for forming serpentine hollow bodies" [15] was filed at the US patent office [12]. The patent called for using fluid instead of the previous method of interlocking mandrels to form cylindrical components and specified that the fluid "is preferably of melted lead" [15]. It is unclear if the patent was ever physically tested and optimized, but was almost certainly never put to any serious commercial use. A few decades later, in 1939, a process for manufacturing "seamless copper fittings with $\mathrm{T}$ protrusions using a combination of internal pressure and axial load" [2] was patented which allowed for $\mathrm{T}$ fittings to be manufactured from straight lengths of pipe using hydroforming with axial feeding [16]. And although initially limited to the manufacture of plumbing fittings, the process was essentially the same physical process that is used today. In subsequent decades the applications of tube hydroforming slowly expanded to include various fittings, simple airplane blades, and bicycle frame joints [12].

In 1986 a patent was issued in North America [17] to the predecessor of a company now called Veri-Form for "the applications of hydroforming technique to larger frame members" [12]. This technology led to the manufacture of large structural components and caused sales of equipment to grow rapidly after 1990 as lots of applications were found in the automotive industry. Sales carried through until about 2006 when new equipment purchases started to match machine obsolescence. Component production continued on the available equipment with one company reporting an increase in $10 \%$ per year from
2010 to 2013 [18], but this increase in production appears to be primarily accounted for by increased machine throughput. Figure 3 shows the approximate number of tube hydroforming machines installed in Europe from 1990 to present.

The data suggests that the hydroforming boom of the late 20th and early 21 st centuries caused by the adoption of the technology for the manufacture of structural elements of automotive products has reached current market saturation.

\section{Sheet hydroforming history}

The first instances of sheet hydroforming operations took place in the 1890s although most of the industrial development did not start for several decades [3]. Based upon the limited amount of technical information and lack of patents during this time it is likely that industrial applications were limited until the Cincinnati Milacron group (now Milacron LLC) created and sold simple sheet hydroforming machines in the 1940s in the United States. Once available, these machines became a standard piece of equipment in the forming industry and worked well in low volume areas as they used one tool instead of two which dramatically reduces the "per part" cost of manufacturing. Cheaper overall costs for smaller quantities are still one of the reasons that companies choose hydroforming technology as demonstrated by one recent breakeven analysis which estimates that under normal circumstances hydroforming is cheaper per part until sizes of around 35-40 thousand parts [20]. In certain cases hydroforming can also use one tool when it would take conventional cold forming processes several iterative tools to create a specific geometry. This means that cost is dependent on both volume and complexity [21].

Other companies tried to copy this technology without infringing upon the intellectual property, some did this by locating the fluid below the part and using the blank as a bladder, but this was ultimately commercially unsuccessful which allowed for Cincinnati to become the predominant vendor of
Fig. 3 Automotive tube hydroforming equipment available in Europe; courtesy of Salzgitter Hydroforming [19]




SHF equipment in the United States in the mid-twentieth century. Many of the early punch hydroforming machines generated fluid pressure in large part from the punch engaging and deforming the metal which displaced the fluid and increased the pressure. These kinds of machines lacked the fine detail and control available on modern equipment in part due to the design constraint imposed by the punch applying a large quantity of the required fluid pressure. While any pressure combination could be set, it would not necessarily be achievable because the punch would move quickly and displace a large volume of fluid which rapidly builds pressure. Also early machines were each quirky in individual ways and in order to run a forming shop efficiently it took operators with experience not just with Cincinnati machines, but with a single particular machine to know quirks of that specific machine and use it effectively. The pressures on different machines would not behave in the exact same fashion and a single machine would perform differently throughout the day as the oil heated up and the resulting change in viscosity affected the forming process. This meant that the operator would have to change the settings slightly throughout the day to compensate and over or under set the pressure based upon experience [21].

Shortly after Cincinnati introduced punch hydroforming equipment in the United States, fluid cell presses were developed in the 1950's which enabled small size forming operations in cavity and punch. This technology was limited in draw depth but had a superior ability to draw in material as compared to rubber pad forming because the fluid cell could exert pressure in other orientations than the forming direction, and the technology was much more consistent than hand forming. Fluid cell presses were accepted into the aerospace industry in the 1960's [6]. Current technologies do not have the same technical limitations that earlier sheet hydroforming machines were encumbered by. Newer machines can generally hit \pm 0.002 of an inch with draw depths and $\pm 2 \%$ with regard to the fluid pressure [21] and have the capacity for deeper draws.

\section{Shell hydroforming history}

Shell hydroforming is the smallest of the three categories and was only invented in 1985 (patented in China in 1988) [9]. Reported applications are limited in scope to small scale projects, academic research, and small batch industrial projects. Shell hydroformed structures are manufactured individually by fabricating (e.g. welding) sheet metal blanks and then inflating the resulting geometries [13] with either specialized equipment or in some cases with high-pressure washers [22]. However, because this process makes components one at a time it appears to be highly labor intensive.

\section{Tube hydroforming applications}

While hydroforming technology is currently used in the manufacturing sectors of many different industries, the development has been pushed most notably by the automotive industry which has used hydroforming technology to greatly improve the manufacturing processes of many different components. Many of the structural members of the automobile are now made via a manufacturing method that includes hydroforming. Tube hydroforming examples of these would include: cradles [10], pillars, [23] and undercarriages [24]. Undercarriages for vehicles were previously (and are still sometimes) "made of U-shaped or channel sections carefully shaped and then welded or riveted together" [25]. The Ushaped sections were produced by rolling and bending sheet metal or by directly rolling a U-shaped channel and cutting and welding it to others. But these sections can not be customized to the same extent as hydroformed components. This is because even though channels can be shaped, their overall cross section can not be dramatically changed. Furthermore because a weld is a compromise in the design, it will introduce a change in material properties and is often a source of increased manufacturing cost and potential defects. This means welds require thicker sections and wider safety margins which add cost and weight. Tube hydroforming removes these problems as it allows for tubes to be bent (instead of welded) while in a tubular shape, and then expanded to final geometry while becoming more rigid through strain hardening. Actual examples of large tube hydroforming chassis structures can be seen in Fig. 4.

Other examples of automotive components changed to a THF based manufacturing processes can be seen in Fig. 5 . These examples contain automotive structures found in various locations around a car including manifolds, pipes, shafts, rotating engine components, bumpers, engine cradles and structural members.

Because of the complicated geometries involved in engine cradles, the implementation of tube hydroforming in

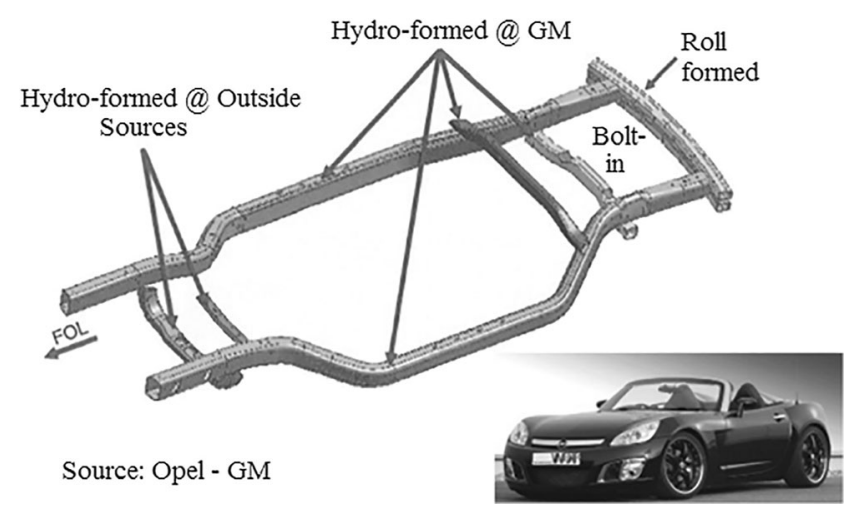

Fig. 4 Automotive undercarriage tube hydroforming applications; reprinted by permission from Springer Nature: Int J Mater Form, [23] 
Fig. 5 Various tube hydroforming automotive applications; reprinted with permission from [24]

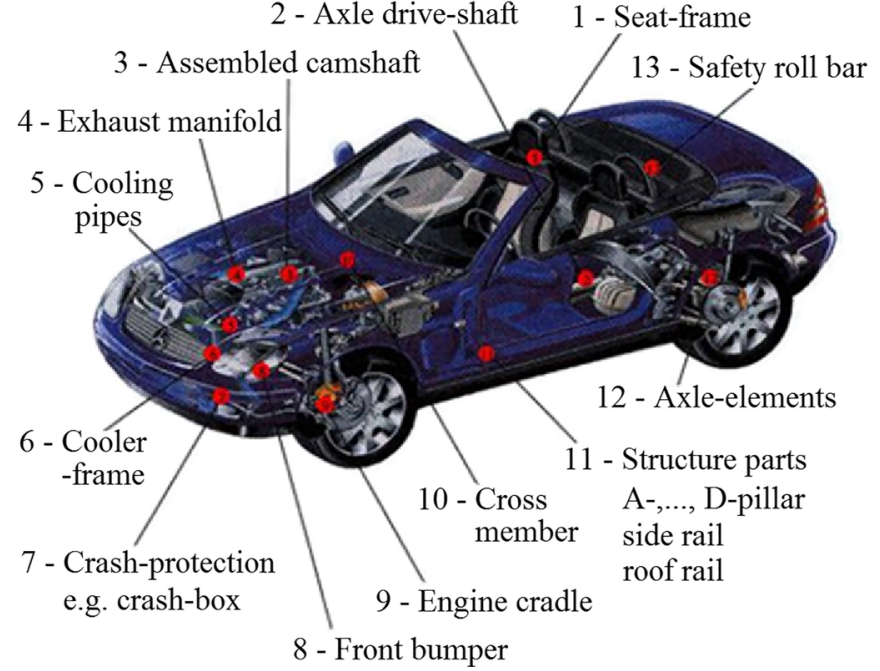

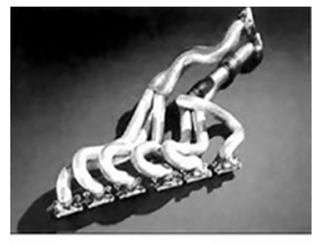
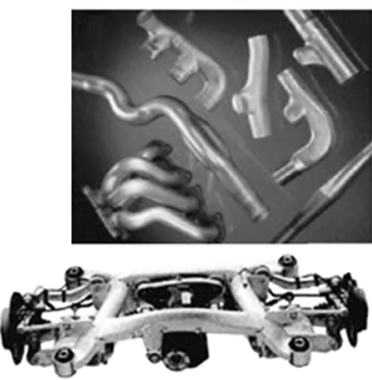

the manufacturing process has greatly simplified the steps in fabrication and reduced the part count. This is because tube hydroforming allows for the creation of geometries which have variable cross sections. This helps in a few ways, for example the variable cross sections can have many flat areas which can be drilled and tapped into, and this would eliminate the need for brackets in those locations. In this way tube hydroforming simplifies the fastening methods required to attach it to the engine and chassis. In one specific tube hydroforming example, a Buick Le Sabre engine cradle had its part count reduced from 40 to 18 when it switched from a conventional to a tube hydroforming manufacturing process [6].

\section{Sheet hydroforming applications}

There are also many sheet hydroforming components found in the automotive including door panels [26], roofs, [23] and various structural frames [27], but because the process is more expensive than regular pressing operations the applications are fewer and more specialized. Still, sheet hydroforming can be an attractive manufacturing process because of its higher formability and superior surface finish. Sheet hydroforming is a near net shape manufacturing process which means that the parts it produces are close to the final specified geometry and require minimal rework. Sheet hydroforming can also be used to produce semifinished geometries which are parts that will be later used in an assembly to make a final component. In this way, the advantages of hydroforming can be realized in a complicated assembly while minimizing the impact of the increased costs imposed by the longer cycle times. Some automotive examples are shown in Fig. 6 and include various structural members, panels, hoods, and doors. Other representative geometries are shown in Fig. 7.

\section{Shell hydroforming applications}

Shell hydroforming appears to have few industrial applications. This is most likely due to the manufacturing method being labor intensive with each geometry being created individually and the relatively recent invention of the subcategory as a whole [9]. There are references in the literature to the creation of fluid holding vessels, fuel tanks and other hollow geometries but these references are few in number which indicates the applications of the technology.

\section{Process parameters}

During any manufacturing processes there are certain process parameters that need to be set and controlled in order
Fig. 6 Automotive sheet hydroforming applications; Reprinted by permission from Springer: Int J Mater Form, [23]

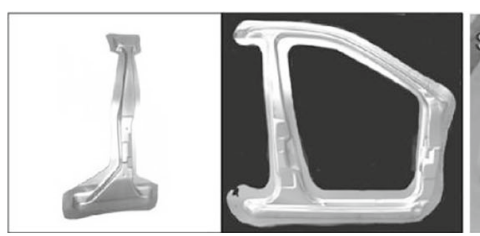

Automotive structural elements



Automotive hood

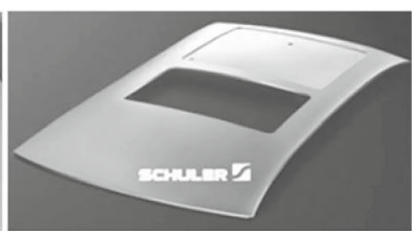

Automotive roof 


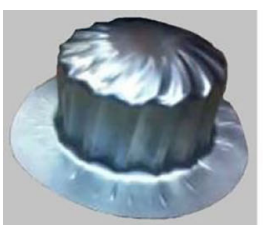

Aluminum Spiral Cap

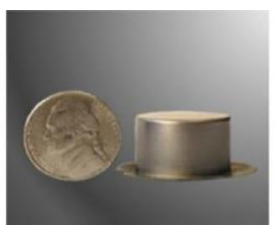

Tiny Niobium Cup

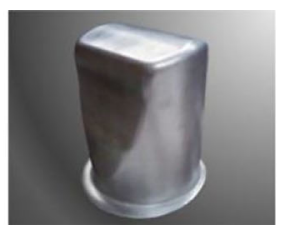

Slat-track can for Airbus A320

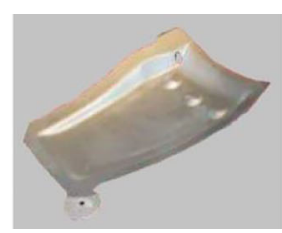

Aluminum Muffler



Inconel Turbine Component

Fig. 7 Various sheet hydroforming components courtesy of Beckwood/Triform

to have a working process. Often in a manufacturing process the more important of these parameters are known as "key process variables" and the less important are dismissed as negligible or are considered impractical to change. The following section outlines the key process variables and different kinds of operations available for each hydroforming subcategory.

Indicative values for the key process variables in hydroforming are as follows. Cycle times in hydroforming operations can be anywhere between $15 \mathrm{~s}$ for very simple operations to over a minute [28]. Pressures in simple lower pressure hydroforming operations are generally kept under 1000 bar but pressure intensification systems on high pressure hydroforming equipment can reach between 1000 to 4000 bar. Exceeding 4000 bar is possible but decreases the service life of the equipment while drastically increasing its complexity [6]. Hydroforming has historically been a cold forming operation because it is difficult to have high temperature surfaces in close proximity to fluids and rubbers but higher temperature applications have recently become more commonplace. Warm hydroforming can still use fluids in temperatures a few hundred degrees above ambient conditions while suffering moderately more damage to wear pads. However, for temperatures over $350^{\circ} \mathrm{C}$, fluids are generally not acceptable [29] and using hot gas or an alternate media (e.g. ceramic beads) is required.

\section{Tube hydroforming process}

The THF operation starts with a tubular blank and expands it into a predefined shape of larger and more complicated cross section by filling the tube with fluid and increasing the pressure to bulge the tube outwards against a die. In most cases the tubes are also forced axially inwards through the use of rams during the process. This feeds in new material which replaces the material that would otherwise be thinning during the expansion. This process along with a typical pressure cycle can be seen in Fig. 8 .

\section{Tube hydroforming blanks \& key process variables}

Both seamed and seamless tube can be used for hydroforming, although the latter must be oriented so that the join is subjected to minimal strain during the forming process (e.g. downward in Fig. 8). In cases with more complicated shapes, preforming operations such as bending must occur before the tubes can be loaded into the dies. In specific cases specialized tailor welded blanks can be used but this adds weld lines, manufacturing complexities, simulation complexities, and other costs. The main variables in tube hydroforming are: fluid pressure cycle, axial pressure (or displacement), lubrication condition (friction), and temperature

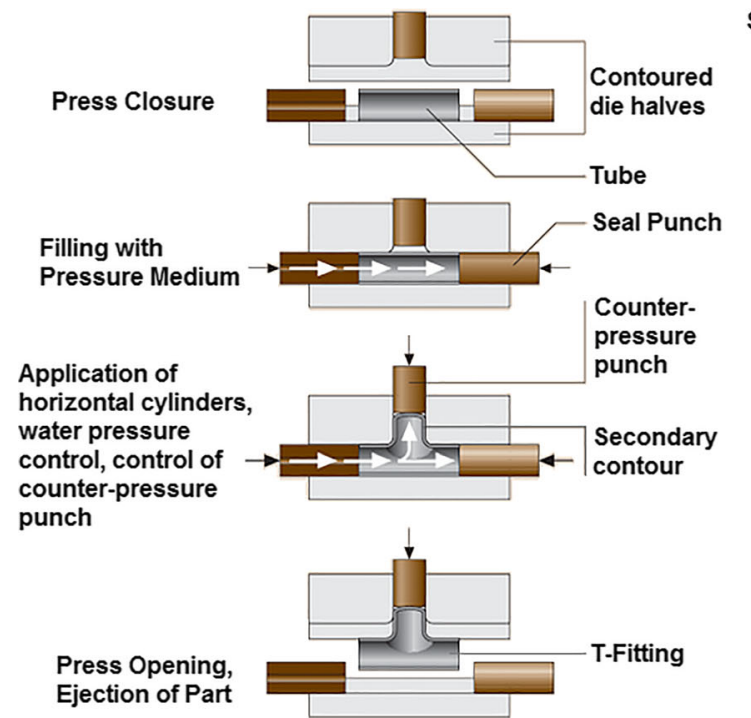

Stroke Pressure Force

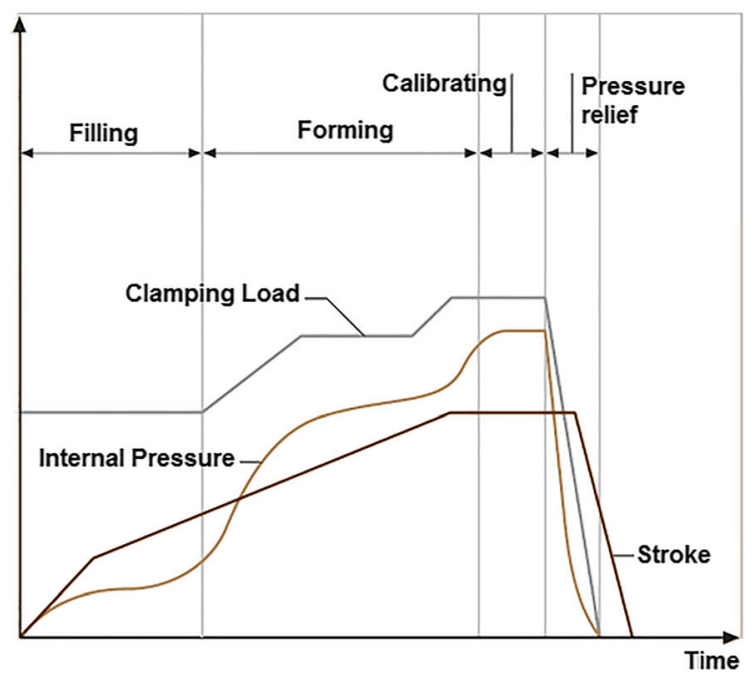

Fig. 8 Tube hydroforming schematic \& cycle; reprinted/adapted by permission from Springer Nature [30] 
[6]. There is also a decision of whether or not crushing or bending operations will take place before the actual hydroforming operation. Processes like axial upsetting can create some of the same features and can also use axial feeding to replace material in a similar fashion to tube hydroforming [31] (as well as create tube flanges [32]).

\section{Tube crushing}

It can be advantageous to have the closing action of the press either crush the tube or carry out some of the forming action while the dies close together. This allows a larger diameter tube to be used then would otherwise physically fit inside the die, which in turn allows for more material to be present during forming (Fig. 9). However a crushing operation work hardens the tube which consumes material formability during the crushing operation [6] and may create pinch points or geometric features (like wrinkles) that will not expand properly in the forming stage.

For an industrial example, one study by Saboori et al. documents the effectiveness of a tube crushing operation followed by a hydroforming operation to produce a $0.9 \mathrm{~mm}$ thick Inconel 718 turbine blade [33]. The process was crushed and expanded through hydroforming to see how much of a $\mathrm{V}$ could be introduced into the tube before the tube burst (Fig. 9 and 10)

\section{Low versus high pressure hydroforming}

Tube hydroforming operations can either be carried out at high or low pressures. Higher pressures allow for more expansion, but material thinning increases in direct proportion to geometric expansion. Low pressure hydroforming takes advantage of the tube crushing concept by first filling the tube with pressurized fluid, and then using the closing force of the press to get the tube either close to, or in to its final shape. When comparing a finite element analysis (FEA) simulation of high vs low pressure tube hydroforming of high strength steels Nikhare et al., 2009 found a smaller press is required for a low pressure tube hydroforming operation [35]. A similar result is also stated by Morphy et al., 1998 who present a
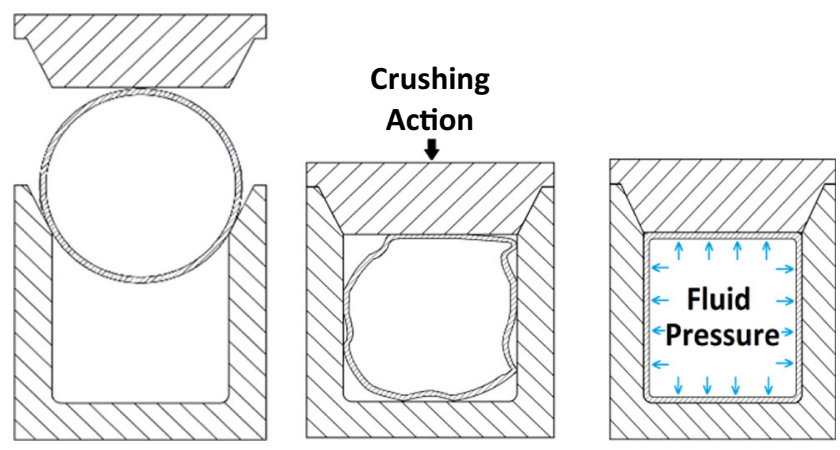

Fig. 9 Low Pressure Tube Hydroforming with crushing operation comparison of two similar engine cradles, one made by high and one by low pressure THF. The research found that low pressure hydroforming (referred to as pressure sequence hydroforming in the source) was advantageous in "processing steps, hydroforming equipment, energy consumption, cycle time, and floor space" [36].

\section{Sheet hydroforming process}

\section{Sheet hydroforming blanks \& key process variables}

Blanks come in the form of rolled sheet metal which is pre-cut to an appropriate size for the operation. Generally, the size and shape of the blank is determined by the results of iterative simulations which can optimize the blank size to allow for maximum material flow around a punch or in to a cavity [37]. In both sheet and punch hydroforming the key process variables to be considered are: the pressure cycle (i.e. the variation of pressure over time), and the temperature, and additionally for punch hydroforming the punch displacement is a key process variable. There are also a few different setup variables such as: whether or not spacers or draw-beads are used [38], the pressure from a counter punch (if applicable), the blank holding force (if the blank is physically held), lubrication condition (friction), blank shape [38], and whether a bladder is used between the fluid and workpiece [1].

\section{Cavity vs punch sheet hydroforming}

The sheet hydroforming process is typically performed by use of either a cavity die or a punch, and punch hydroforming is presently commonly known as hydromechanical deep drawing [39]. Both of these processes can be seen schematically in Fig. 11. Which process is chosen is dependent upon the geometrical complexity and draw depth of the part being formed. If a part has a complicated surface (e.g. with many different bulges) then it will likely require a cavity die. If a part has a cylindrical geometry and simple (flat or curved) surface then a punch will be beneficial as it can perform a deeper draw [3]. The tradeoff is generally that presses which use a punch have a smaller bed size as compared to those with a cavity and can only draw simpler shapes, but can make deeper draws with less material thinning.

\section{Bladder vs direct fluid contact}

Some sheet hydroforming systems such as ones manufactured by Quintus Technologies [40] or Triform Presses [41] use a flexible bladder as an intermediary between the fluid and blank, while other equipment vendors like FF FluidForming [42] allow the fluid to be in direct contact with the blank. Bladders can reduce degreasing operations by keeping working fluid away 
Fig. 10 Crushing and tube hydroforming process of a turbine blade in the initial and final stages; reprinted by permission from ASME: ASME Turbo Expo 2015: Turbine Technical Conference and Exposition [34]

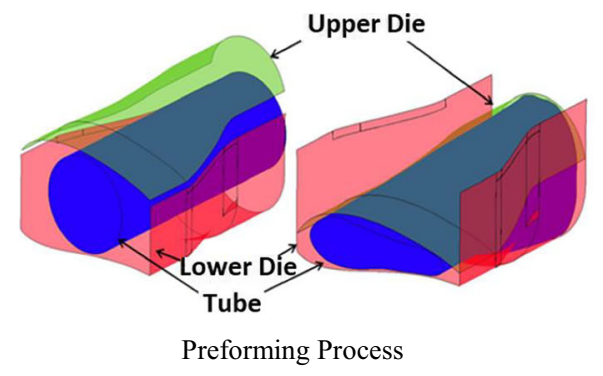

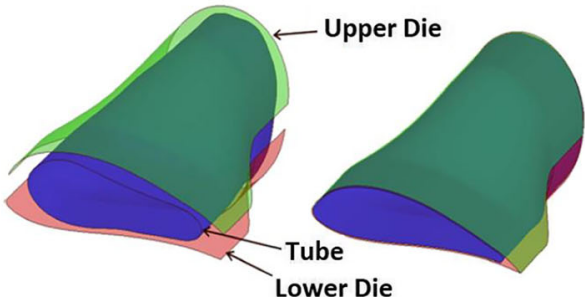

Tube Hydroforming Process

from blanks. This also keeps lubricant from getting into the working fluid. They also improve surface quality and possibly allow for more intricate feature generation, but rubber bladders have a finite life, need to be replaced, and sometimes break unexpectedly, they also lower process efficiency and require heavier presses [1]. While each equipment manufacturer has their own rationale about why they do or do not use bladders, the impact they make on the draw ratio appears to be minimal.

One important point to note about the use of a bladder is that it can enable the use of certain forming techniques such as a circular pressure intensifier that tightens radii (discussed and shown in detail later in Fig. 33). Without a bladder, the fluid would leak around the pressure intensifier instead of applying a forming force. A schematic of hydroforming with a punch and bladder can be seen in Fig. 12.

\section{Fluid cell presses}

There is also a relatively new type of hydroforming press (developed in the 1950's) called a "fluid cell press" which is quite versatile as it has an extendable fluid cell tray on which lots of various blanks and dies can be laid out [6]. After it has been loaded up, the bed slides into a press and underneath a pressurized bladder [40]. With these machines the bed size is large and both cavity and punch dies can be used. Also all of the tools that the operator can fit on the bed can be used simultaneously [20]. While versatile, these presses generally are limited by a relatively shallow draw depth. This concept can be seen before and after pressurization in Figs. 13 and 14 respectively.

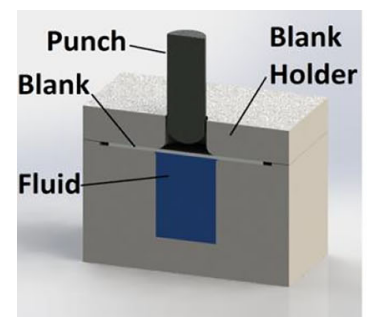

a) Before

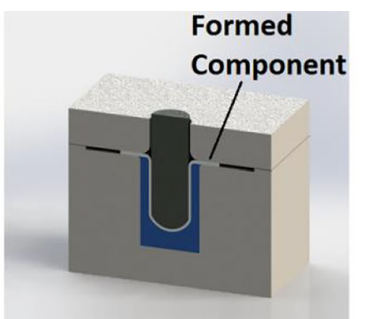

b) After

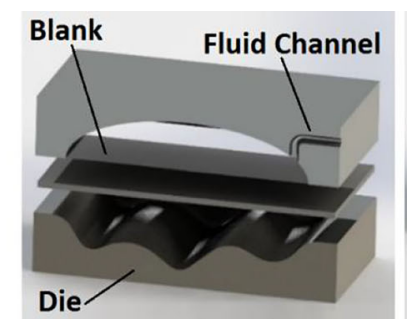

c) Before

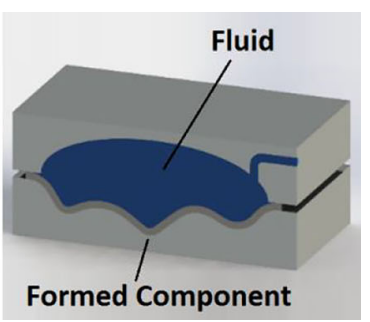

d) After
Fluid cell presses are efficient for light duty hydroforming operations especially in industrial applications which require versatility as they accommodate quick tooling changes, offer multiple operations per pressurization and do not suffer from alignment issues. Additionally, they also excel at large sheet metal components which contain many fine details.

\section{Shell hydroforming process}

A shell hydroforming process is generally die-less and is useful for creating custom hollow geometries especially in large sizes where dies and presses are expensive. The shell hydroforming operation starts with sheet metal blanks which are cut and welded together and inflated through use of a nozzle. Like the other hydroforming categories, shell hydroforming can be subcategorized into smaller groups based upon the geometry and pattern of the blanks used.

The fluid pressure cycle, and the blank welding pattern are the main key process variables in shell hydroforming. Various options for shell hydroforming welding patterns can be seen in Fig. 15.

\section{Process windows and loading paths}

A "process window" has a range of values that work for a given process and are displayed graphically. These windows are generated through simulation and experimentation and are governed by the material properties and the geometry of the parts. In specific circumstances, companies can also set the physical limitations of their equipment as boundaries to the process window. A schematic example of a simple process window can be seen in Fig. 16 and an empirically derived

Fig. 11 Schematic illustration of punch $(\mathbf{a}, \mathbf{b})$ and cavity $(\mathbf{c}, \mathbf{d})$ hydroforming 


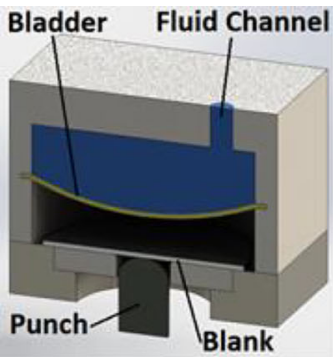

a) Before operation

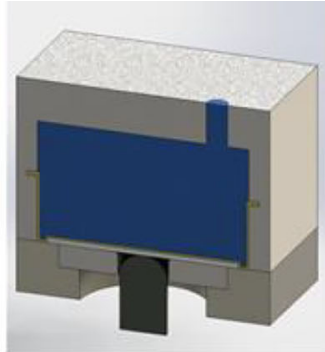

b) Pressure increased

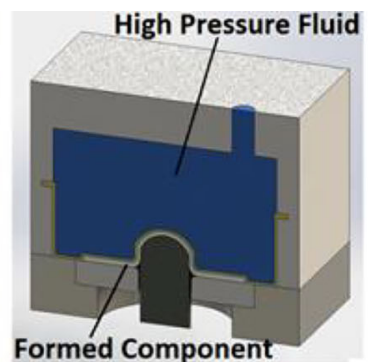

c) Punch engaged

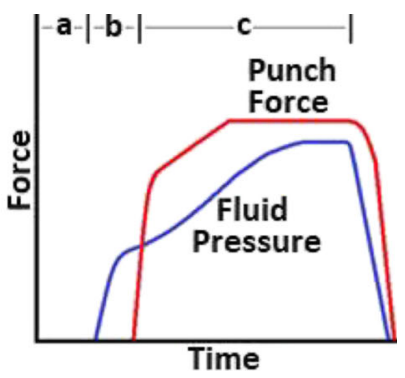

Pressure curve

Fig. 12 Schematic of punch hydroforming with a bladder

process window created by Hashemi et al., can be seen in Fig. 17. In this context, a "sound" part is one of an acceptable quality (free of wrinkles and ruptures) and a desired forming area is identified in the middle of the sound part area.

Load paths are similar to process windows except instead of defining the range of viable process parameters they produce a specific sequence of values employed during a forming operation to produce a desired result. The load path is the critical setting in a hydroforming operation as it is the forces applied on a blank to go from a piece of sheet metal to a final component. A load path is a statement of how much fluid pressure (and axial force in the case of tube hydroforming) is applied at a given time through a forming process. They are created by "iterative finite element analyses with adjustments based on forming experience... due to the highly nonlinear nature of the tube hydroforming process" [45]. There are numerous studies in the relevant literature which explore how process windows and load paths are created and how they can be expanded or optimized but there are many challenges in doing so. For example, Bagherzadeh et al. formed bimetallic sheets in a SHF process and constructed a process window based upon FEA results and trials [39]. Wang et al. calculated a process window with "the stress analytical model combining material properties with workpiece geometrical features" in a SHF operation and relate which parts of the pressure cycle are important to which features in the component [46]. Shin et al. devised a process window for a THF operation and then enlarged it by reducing localized strain in vulnerable areas inhibited necking and subsequent failure [47].

Several studies cite process variability as a key difficulty in load path optimization and have proposed various means to take this into account. For example, Abdessalem et al. use a probabilistic approach to account for variation during load path creation [48], while Huang et al. propose a kriging-based non-probability system [49] which only requires the bounds of uncertainty instead of a probabilistic function (presumably because this information is generally easier to acquire). Other studies tried to optimize load paths with fuzzy logic, [50] or by statistical means [51] or with metamodeling techniques to cut down on computational time [52].

One key area which is repeatedly described in the recent literature (albeit by different names) is the process of optimizing a load path using multivariable optimization functions. This differs from classic simulation methods which perform an analysis given a predefined set of parameters and determine the outcome. Multivariable load path optimization instead steps through the process and optimizes at each step. Abdessalem et al. performed a multi-objective optimization of the loading path in a tube hydroforming operation (using metamodeling) [52]. Brooghani et al. used a "multilevel response surface method" for optimization of a load path which found the optimal point (based on minimal thinning in FEA simulation) at each interval and proceeded accordingly [51]. Alternately, instead of designing a specific function ahead of time, Xiang et al. looked at 9 different theoretical load paths and made a determination about which was best by looking at their effects on the results of an FEA analysis [53]. Intarakumthornichai et al. used a genetic algorithm based upon a two part quality criteria (minimization of thinning and elimination of wrinkles) [45]. Ge et al. used a similar multiobjective optimization function with differential evolution in a tube hydroforming operation to optimize a loading path [54].

\section{Analytical methods and numerical simulations}

Once reserved for specialized scientists, finite element analysis is now an integral part of complicated forming operations due to the increase in computational power and the increased
Fig. 13 Sheet hydroforming fluid cell press before pressurization

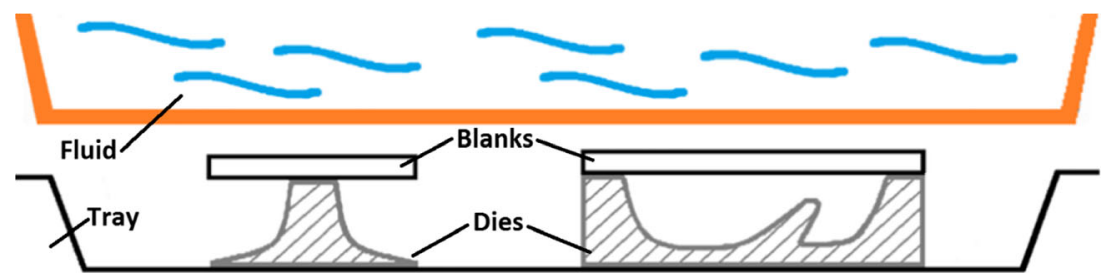


Fig. 14 Sheet hydroforming fluid cell press after pressurization

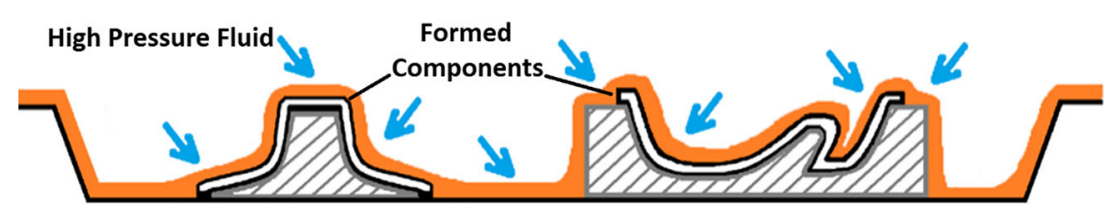

diversity, accessibility, and user friendliness of software packages. That said, in comparison to other forming processes such as stamping, hydroforming is a difficult process to simulate because of the addition of fluid pressure, rubber diaphragms and the combination of axial forces and fluid pressure present in tube hydroforming.

As mentioned in the previous section, a key component in recent hydroforming research is the accurate optimization of the loading path and a lot of the recent research in analytical methods has been directed towards that ends. In general, the fluid pressure is assumed to be hydrostatic and universal throughout the application and follow the pressure curve. These kinds of simulations enable the hydroforming process by allowing for the optimization of a function (often based upon minimal material thinning and wrinkling) [45] instead of a more traditional empirically derived equation method, e.g. a calculation of a pressure curve that suppresses buckling using the energy method [55]. These simulations progress systematically and choose the optimum fluid pressure based upon the best outcome at each iteration. Muhammad et al., describe in their review of forming processes the preference of using continuum elements in hydroforming as they are "capable of describing deformation in thickness directions" [56].

Many new papers suggest applying the concept of "simulated annealing" to the optimization of hydroforming processes. Simulated annealing is one of the most popular metaheuristic algorithms used to solve optimization problems [57] and gets its name from classical annealing (the process of softening metal by heating and slowly cooling to freeze the structure at a minimum energy state) [58]. Simulated annealing is a probabilistic technique for approximating the global optimum which is used in complicated situations where finding an exact maximum is not realistic. Hashemi et al. successfully used a sheet hydroforming process to form bilayer composite sheets and simulated the process using a simulated annealing algorithm [57]. Mirzaali et al. used a simulated annealing optimization algorithm along with a 2D FEA simulation to optimize axisymmetric tubes in a THF operation [59].

Another key area in the research is the implementation of "fuzzy logic" which, as opposed to Boolean logic, can use any value between 0 and 1 [50] this means it can handle information that is partially true. Öztürk et al., implemented a fuzzy logic technique to optimize the loading profile in a sheet hydroforming operation using a punch to deep draw aluminum alloy sheets [60]. Similarly Ge et al. used fuzzy logic theory to create load path in a tube hydroforming operation [50], and Manabe et al. used an in-process fuzzy control system to hydroform T-shaped tubes [61] proving that fuzzy logic can be used during the process as well.

There is no straight forward answer to which of these methods generates the best results during these loading paths. The techniques are not necessarily mutually exclusive and all have their own cost in terms of computational requirements. Multi objective optimization can be performed in probabilistic or non-probabilistic environments and can take tolerances and variation into account. Having a probability function for the variables in the hydroforming process produces better results in finite element analysis [48] but is not required and other recent examples of using only the bounds of uncertainty have also been successful [49]. Success has been had with simulations that use fuzzy logic, simulated annealing, and traditional modelling techniques and so selection choose comes down to a mix of application, complexity, and experience. For further reference numerous reviews have been written on the topic of finite element modelling in sheet metal forming such as: Ablat and Qattawi [62] who review and categorize each type of numerical simulation as well as the yield criteria and software available. Additionally Mackerle et al. [63] describe and list numerous forming papers in different areas, and section 1.1 above lists numerous review papers on hydroforming which include finite element modelling aspects.

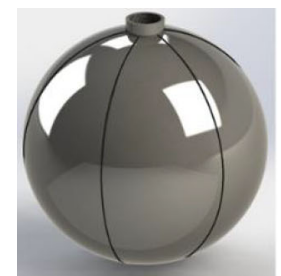

a) Ellipsoidal shell

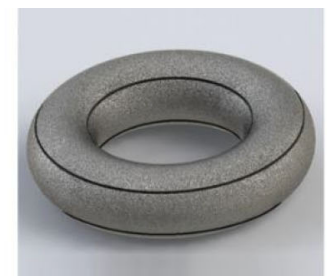

b) Ring shell

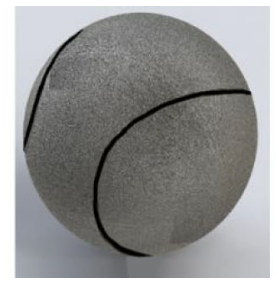

c) Tennis ball shell

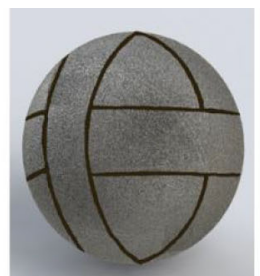

d) Volleyball shell

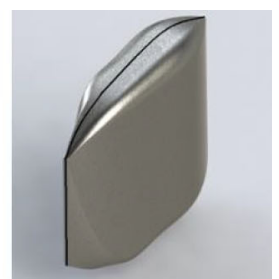

e) Purpose built shell

Fig. 15 Different varieties of blank welding patterns; redrawn from [9] a-d, [22] e 


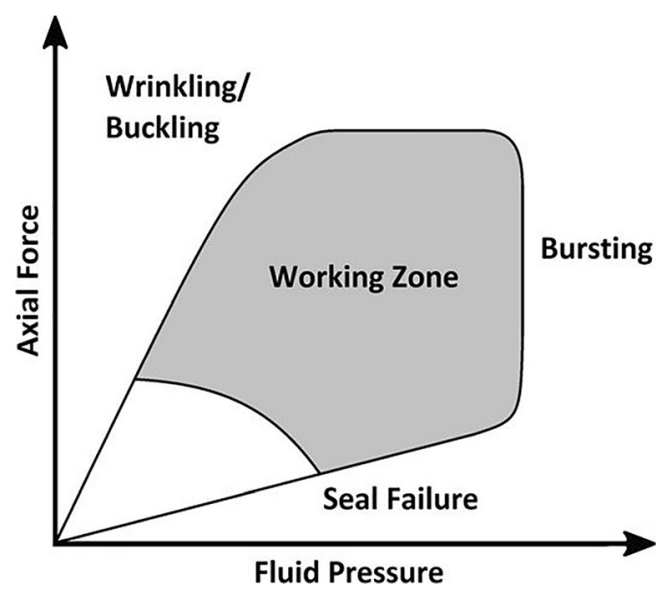

Fig. 16 Typical schematic of a tube hydroforming process window; as described in [43]

\section{Forming limit diagrams and curves}

Although process windows provide valuable insight into the functional range of a particular hydroforming machine they are by their nature only applicable to specific machines. In contrast forming limit curves (FLC represent limits in terms of the material parameters (e.g. stress, strain) and consequently provide a machine independent view of process capability. The forming limit curve is produced by analyzing the way a material stretches during a forming operation and observing the limits of a material's behavior. To do this, many samples of a given material are deformed in a variety of orientations while optically analyzing the surface such as in a Nakajima or Marciniak test [64].

Nakajima tests, (Fig. 18) use photogrammetry to calculate the major and minor strains during a forming process. Forming limit diagrams have been adapted to be suitable for use with newer hydroforming methods such as pulsating fluid loads (explained in section 6) [65]. Examples of FLDs can be seen in (Figs. 19 and 20).

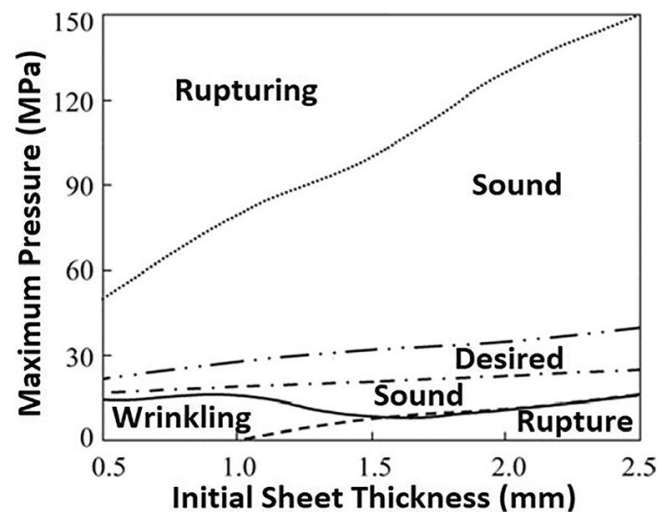

Fig. 17 Empirically derived tube hydroforming process window; reprinted by permission from Elsevier: Transactions of Nonferrous Metals Society of China [44]
The resulting curves can play an important role as they can be used in combination with simulation software to predict failure during a forming process.

\section{Tribology}

The interaction of surfaces and lubricants is a key factor in the performance of a hydroforming process. While generally the objective in a forming operation is to reduce friction to allow material flow (usually by adding lubricant), friction can be useful in controlling material flow by reducing thinning in important areas. Several large studies have been carried out to investigate tribological issues in the THF process such as Koç who proposes guidelines for lubricant selection and concludes that axial feeding, axial force, and part thickness are strong indicators of lubricant performance [67]. Similarly Ngaile et al. provide an overview of the challenges of tribology in tube hydroforming operations and discuss tests to evaluate friction conditions [68]. Ma et al. look into the recent research for measuring the friction coefficient for high strain rate forming and evaluate the methods in the literature for measuring friction coefficients for tube hydroforming at high strain rates [69].

Other studies focus on specific applications or optimization of tribological conditions such as Abdelkefi et al. who evaluated the friction coefficient by using a tube hydroforming operation in a square die (similar to the corner filling test shown later in Fig. 23) with numerical and experimental means [70]. They found that critical thinning took place in the transition zone between the wall and the corner radius. Rudraksha and Gawande looked at the coefficient of friction in a THF operation and tried to optimize the other process parameters (including geometry) to lower friction. While this approach might not always be possible in industry due to fixed geometric requirements, they were able to reduce the friction coefficient from 0.15 to 0.03 [71]. Wang et al. study tribological factors which influence micro forming (which can be quite different from macro scale tribology during forming) and develop an equation for estimating friction in a micro upsetting procedure [72].

\section{Materials}

\section{Hydroformed materials and alloys available in the literature}

Like all forming/forging operations, hydroforming has greatly differing outcomes depending on which material is used. Stronger materials take a higher forging force to achieve a final shape, and certain materials like Ti-6-4 are extremely difficult to form at room temperature. There is a large body of work concerning the hydroforming of standard steel, 


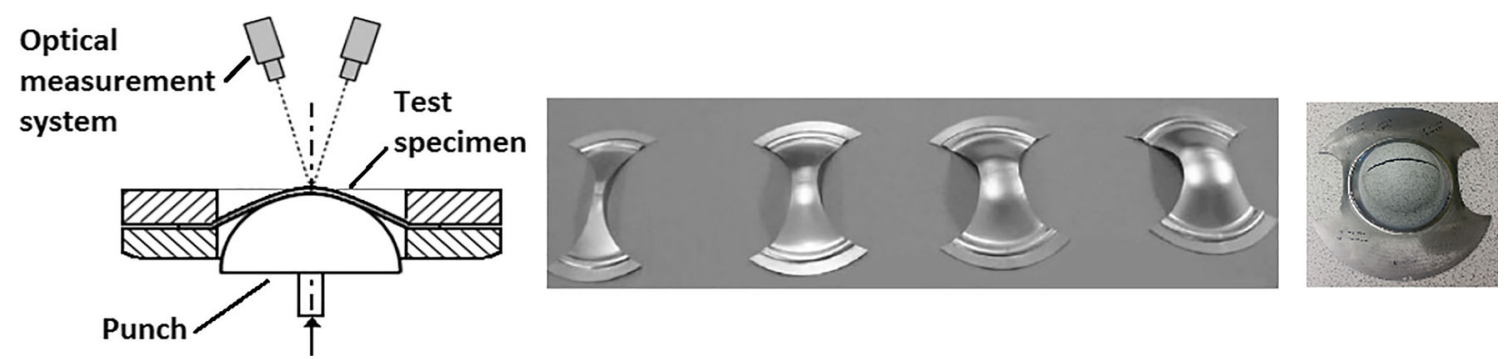

Fig. 18 Nakajima test rig and various assessed geometries; redrawn from [64]

stainless, and aluminum, especially automotive grades of materials as can be seen in a table of common sizes created by Koç, et Al., 2001 [10]. What follows is a representative cross section of the large body of published work on hydroforming materials. Oh, et al., 2006 [73] summarized various tube hydroforming and sheet hydroforming applications in the automotive industry. They gave examples of a tube hydroforming process which produced a tie bar of diameter $48 \mathrm{~mm}$ and thickness $2 \mathrm{~mm}$ using steel grade STKM11A, and a similar operation to produce an engine cradle made from SAPH38P steel. They also discussed a sheet hydroforming operation that produced an engine mount bracket which was also made from SAPH38P steel. Lastly they discussed sheet and tube operations that could produce an engine mount subframe assembly which was also made from SAPH38P steel.

Palumbo, et al., 2006 [74] formed stainless steel samples using a cavity sheet hydroforming operation which utilized a moveable die (or a counterpunch) to produce hemi-toroidal (donut-like) shapes. Parsa \& Darbandi, 2008 [75] used a hydromechanical deep drawing operation to produce an automotive fender in three different materials: St14 steel, IF steel and 2024 aluminum sheet. Abedrabbo, et al., 2009 [76] used a tube hydroforming operation to form high strength steels in various grades (namely DDQ-T1, HSLA350-T1, HSLA350T1, DP600-T1, DP780-T1) and found maximum material thinning at around $10-15 \%$ for an operation that expanded a circular cross section into a box cross section. This research was aimed at tube hydroforming applications in lightweighting automobiles and based on the cross section of

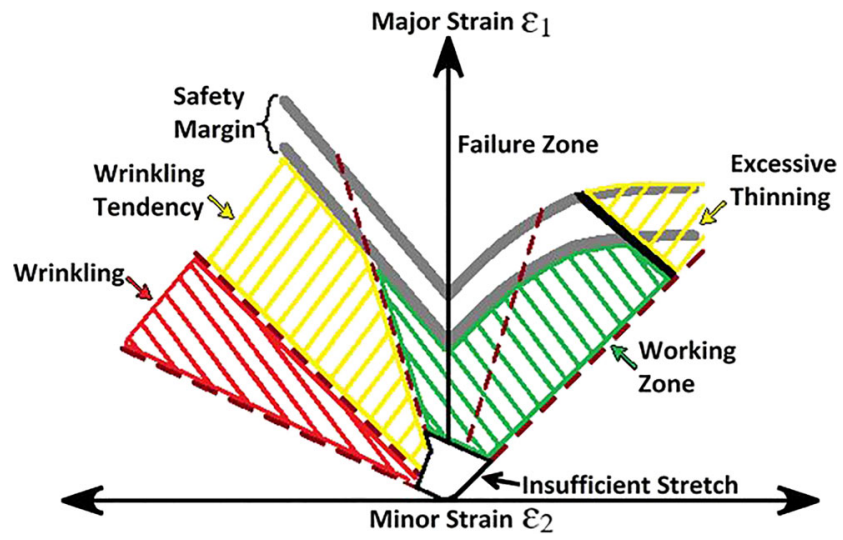

Fig. 19 FLD with areas explained; redrawn from [66] the geometries and alloys in question were likely chassis related geometries.

For other more exotic aerospace materials such as nickel and titanium alloys, information is less readily available in the literature because the commercial opportunities have not been as sufficiently explored. Examples of more exotic materials include Mirzaali, et al., 2012 [77] who optimized loading paths through simulation and validated their results experimentally using ASTM C11000 copper tubes. Choi, et al., 2007 [78] optimized a loading path for AZ31 which is a magnesium alloy but did not validate their results experimentally, only numerically. Djavanroodi \& Derogar, 2010 [79] used a hydromechanical deep drawing process which implemented a small floating disc to produce and evaluate samples of Ti-6-4 and AL6061-T6 aluminum alloy sheets. Mohamed, et al., 2016 [37] performed an FEA simulation and an experiment which consisted of a sheet hydroforming deep drawing operation on Inconel 718 . This experiment required a two-phase operation with an annealing stage in the middle as well as an advanced pressure cycle to form an oval shaped deep drawn component.

As a general rule of thumb, if a material is appropriate for other cold forming operations then it will perform well in a hydroforming process. Of specific benefit to hydroforming are material characteristics such as high ductility, uniform elongation, a large strain hardening coefficient, a fine grain structure [6], and a large difference between yield and tensile strength.

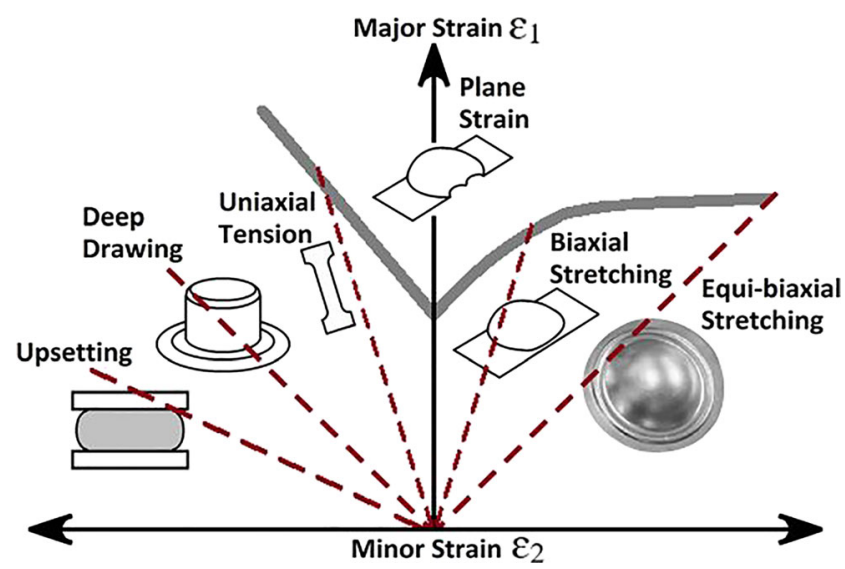

Fig. 20 FLD with application; redrawn from, [66] (diagram) \& [64] (Equi-biaxial stretching example) 


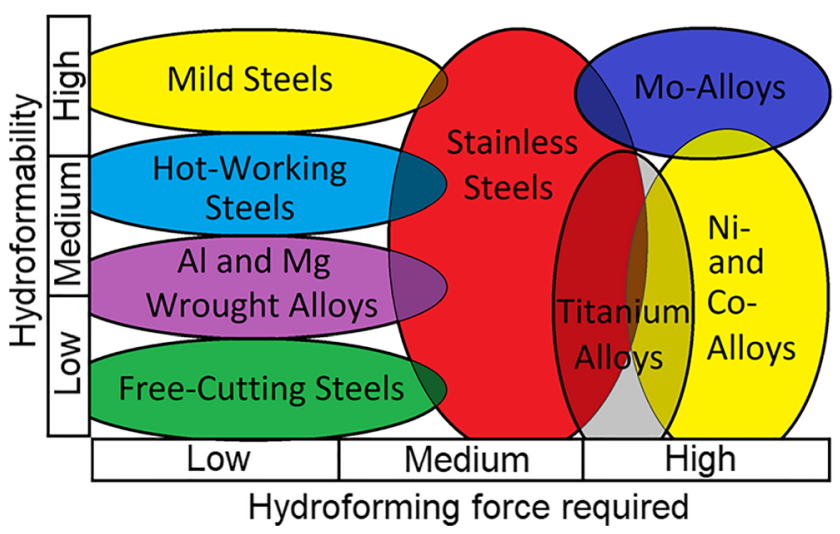

Fig. 21 Forces required to hydroform versus hydroformability by metal; redrawn, translated \& adapted from [80]

During material selection, designers should consider these factors alongside the other application specific design requirements of the component. Furthermore, the pressure which will be required should be calculated and compared to the available equipment before deciding a material (for tube hydroforming Koç et al. suggests using $P k=1.2 * \sigma * \frac{10}{\mathrm{r}}$; where $\mathrm{p}_{\mathrm{k}}$ is final calibration pressure, $\sigma$ is tensile strength, $\mathrm{t}_{0}$ is thickness and $\mathrm{rc}$ is the smallest corner radius) [6]. For a quick reference, Fig. 21 compares hydroformability by material type versus the required forces (press requirements) to form a given material [80].

\section{Typical hydroforming material properties, microstructures and tolerances}

This section gives a qualitative description of the typical material properties and microstructures associated with hydroformed components. General hydroforming operation can be considered to make changes to the components microstructure that are typical of cold forming operations as seen in Fig. 22 (i.e. a grain structure distorted to follow the contours of a components cross-section). Hydroforming (performed at room temperature) like other cold forming processes results in high levels of work hardening (or strain hardening) [81]. This means that it has several advantages over other processes in terms of mechanical and microstructural properties. In cold forming operations, the forces required to form the object are high (as materials are less malleable at low temperatures) but the accuracy is high and the operational costs are low. In hot forming operations, the costs generally increase as the operation becomes more complicated. High temperatures must be induced and maintained, the tendency for oxidization increases so inert gasses (nitrogen or argon) become more relevant and sometimes the accuracy lowers (although this is not always the case) as thermal expansion and contraction becomes relevant. However, the strength and stiffness is still higher than machining or casting as strain hardening occurs [81].

\section{Material characterization}

While tensile tests are traditionally used to characterize materials, more advanced techniques have proven to yield different and often superior information. Examples of these tests are the Nakajima and Marciniak tests described earlier in section 3.4 but also fluid bulging tests that are more physically similar to hydroforming. The hydraulic bulge test is similar to the Nakajima test except instead of a punch, fluid pressure is used to bulge a sheet metal sample (Fig. 23a). The fluid pressure is increased until the specimen fractures in the middle of the bulge while the strain levels on the top are monitored. This allows for the determination of stress strain curves in biaxial stress state [82]. It is now recognized that for tube hydroforming a tube bulging test (Fig. 23b) produces superior data than tensile tests for finite element simulations [83]. The main challenge in industry is the lack of availability of measurement hardware, so while the data is superior, according to Vitu et al., most manufacturers still use tensile information for designing forming operations [83]. The test works in a similar fashion to the hydraulic bulge test (increasing pressure until a rupture at the middle of the tube while measuring strain) except the stock is a tube and axial feeding may or may not be used depending on the setup. Other, more representative tests include using a "corner filling test" (Fig. 23c) which can provide a more representative value for a Coulomb's coefficient than a standard pin on disk test [84] when used in a tube hydroforming operation. A corner fill test pushes metal into a square corner to see how far into the corner the material will form before the material breaks to give an idea of the minimum formable radius possible in a tube hydroforming
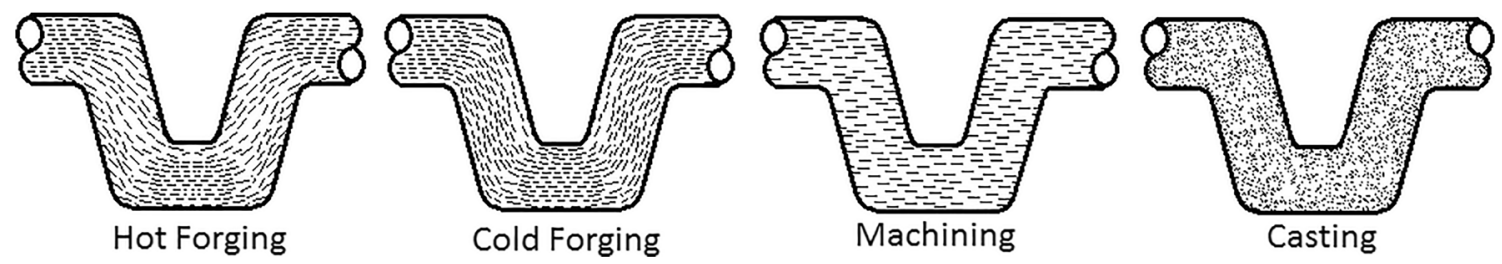

Fig. 22 Grain flow of different manufacturing methods; redrawn from [5, 81] 


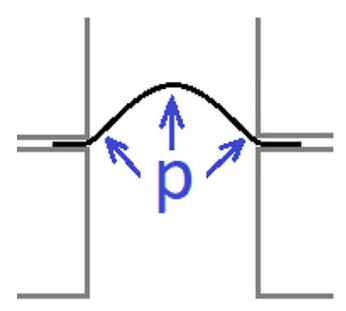

a) Hydraulic bulge test

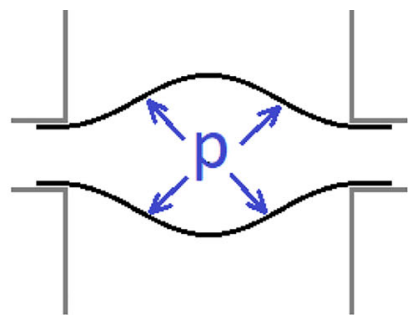

b) Tube bulging test

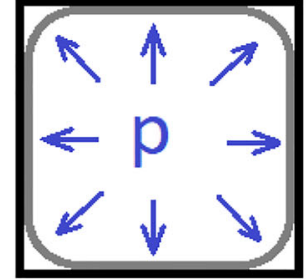

c) Corner filling test

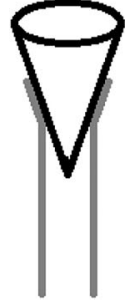

d) Tube-driftexpanding test [86]

Fig. 23 Various kinds of materials characterization tests specific to hydroforming

operation. Other tests for measuring friction in metal forming applications include devices based on stretching of a strip around a pin, or apparatuses that use strain measurements to infer friction forces [85]. A corner fill test uses a tube in a die with a square cross section and gauges how easily or how well the tube conforms to the square corners of the die when the interior fluid pressure is increased. Additionally, tube-driftexpanding tests (Fig. 23d)gauge formability by forcing a cone into a tube until fracture [86]. Eventually the cone will force itself into the tube far enough to cause a split to form on the exterior. The value of the circumference of the tube at the onset of fracture as compared to the original material gives an indication of formability. Examples of some of these tests can be seen in Fig. 23.

\section{Geometry}

\section{Limitations}

There are certain features that make a hydroforming operation difficult or impossible and these features should be avoided during the design phase of a component if at all possible. These limits are general limits for the hydroforming process, but are also dependent on materials to a certain extent. For example, there is always a limit to how deep a draw can be, but a material such as stainless steel will draw far deeper than Ti 6-4 because of the material's superior formability (higher ductility). Features to design out are shown in Fig. 24 and some rules of thumb and limits are identified thereafter from the relevant literature.

\section{Multiple bends}

With a tube hydroforming operation, multiple bends (or bulges/protrusions) in a single tube decrease the ability for the axial feeding motion to replace material that thins during the operation. An illustration of a figure with bends that would inhibit axial feeding can be seen in Fig. 24a. If a tube has one or two sharp bends then it may still be possible to use axial feeding but "if a part has more than two severe bends, axial feeding in the central part of the tube becomes virtually impossible" [6]. Severe bends in this case are 90 degrees or more. Furthermore, pre-bending a tube before hydroforming consumes the formability and can greatly reduce the amount of deformation possible during the hydroforming process. A $2 \mathrm{D}$ bend (a bend with a radius

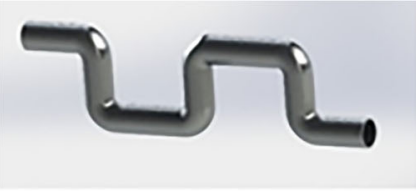

a) Multiple Bends

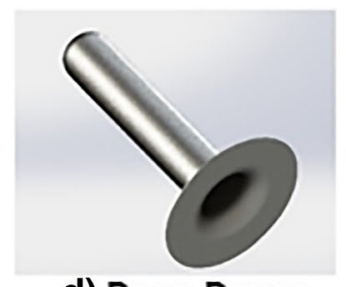

d) Deep Draws



b) Sharp Bends

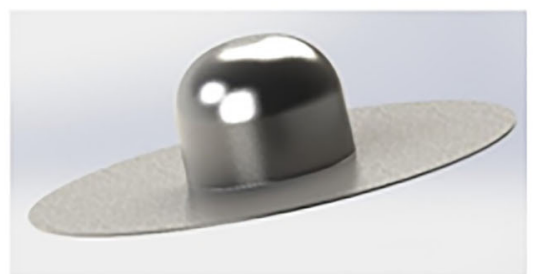

e) Sharp Radii

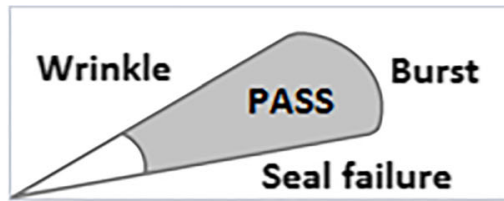

c) Outside Process Window

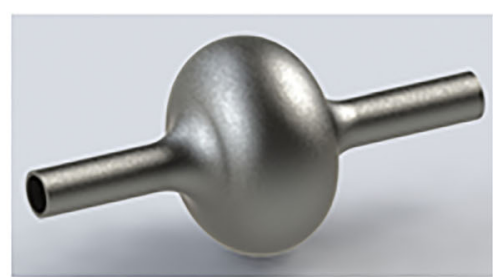

f) Excessive Bulging

Fig. 24 Features that limit hydroformability; 24c redrawn from [43] 
of twice the tube's diameter) leads to approximately $20 \%$ axial strain on the outside of the bend, 1.5D leads to $25 \%$ and $1 \mathrm{D}$ leads to $33 \%$. Koç et al., recommend a minimum bend radius of $1.5 \mathrm{D}$ wherever possible [6]. The extent to which axial feeding assists hydroforming is quantified in section 5.1.5 through use of an equation in the literature.

\section{Sharp bends}

With both sheet and tube hydroforming, sharp bends (as shown in Fig. 24b) should be avoided. With a sheet hydroforming operation, a sharp bend may eliminate the possibility of using a punch. Furthermore, when using a cavity die, the material will have difficulty feeding inwards from the flange if there is a sharp bend. With a tube hydroforming operation, sharp bends will require a large pre-bending operation prior to hydroforming which will consume formability and limit axial flow [6].

\section{Deep draws}

Draws which are exceptionally deep are difficult to create and may require many steps or stress relieving annealing stages. Also special equipment with large draw depths or multiple sets of dies could be necessary. This adds considerable cost in areas such as: development, trials, cycle times, labor, and equipment costs.

One of the benefits of sheet hydroforming is that it allows for more formability which is expressed in terms of an increased draw ratio or aspect ratio. The biggest draw ratio that can be realized in a given operation is known as the "limit draw ratio" (or LDR). Larger LDRs allow for larger blanks to be used and for more material to be drawn in to the working area from the flange. This means a deeper draw made with less material thinning is possible. For normal cold sheet forming operations the limit draw ratio is around 2 , but for hydroforming the value can reach 2.5 [1] or even in specific circumstances over 3, [6]. While this is a generalization (because the limit drawing ratio is dependent on material characteristics as well as geometry) the underlying point is that a component can be drawn more in a hydroforming process than a conventional deep drawing process. This benefit stems from the fact that fluid exerts pressure evenly in all directions over an entire surface and therefore it has an advantage over a traditional pressing operations which employ a metal blank holder controlled by a "blank holder force." Hydroforming controls the fluid system which supplies pressure over the entire blank instead of only at the circumference which increases drawability of the material in the process. This is valuable because if more material draws in from the flange, there is less material thinning in the final component. Similarly, researchers also suggest limiting phenomena such as a "critical fluid-pressure locus above which rupture by tensile instability may occur" [87].

The LDR calculation is a quick calculation that is particularly useful for a designer that has a specific geometry in mind and has to source equipment (or vice versa). The LDR calculation is shown schematically in Fig. 25 where the draw ratio would be: Draw Ratio $=\mathrm{D}_{0} / \mathrm{D}_{\mathrm{f}} ;[6]$ and the maximum $\mathrm{D}_{0} / \mathrm{D}_{\mathrm{f}}$ achievable would be the LDR.

The hydroforming process is generally limited to a LDR of 2 to 3 [1], and the draw depth is generally set to be roughly twice as deep as the punch diameter [21]. If the geometry calls for a larger draw ratio than is possible with the hydroforming process, an alternate manufacturing process must be pursued or multiple drawing stages considered. In certain cases multiple hydroformed components could be drawn to an acceptable draw ratio and welded together.

In a recent study involving the calculation of limit drawing ratio for AZ31B magnesium alloy sheet in a warm deep drawing process Wang et al. [88] investigated the draw ratio by looking at various blank size diameters during the operation as can be seen in Fig. 26. By allowing more material to flow into the cup during the forming operation, the minor strain $\left(\varepsilon_{2}\right)$ becomes compressive allowing for more tensile strain in the major direction $\left(\varepsilon_{1}\right)$. This would be visually represented as a shift of points on the surface of the material to the right in Fig. 19. The balance with hydroforming is that the larger the blank size is, the larger the force on the surface of the blank will be as the more area the fluid will be exerting force over. Too large of a blank size leads to too high of a force which
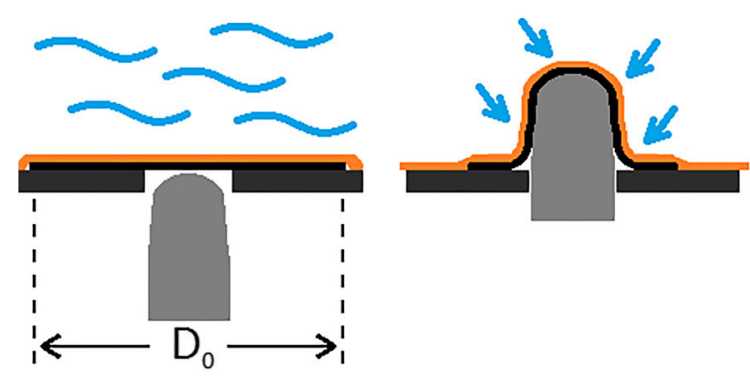

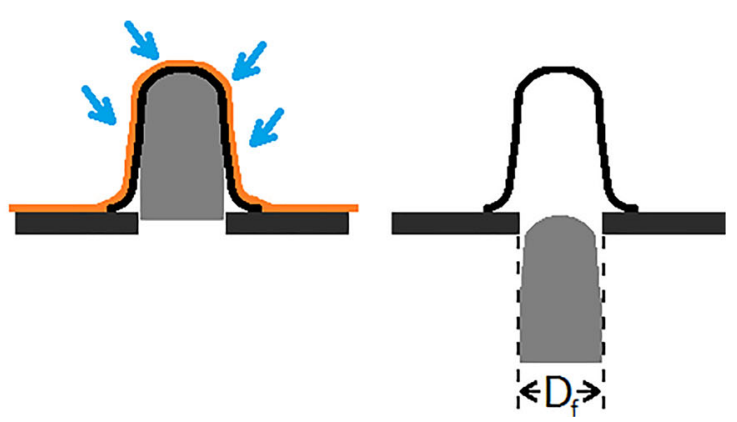

Fig. 25 Draw Ratio Definition $\left(\mathrm{D}_{0} / \mathrm{D}_{\mathrm{f}}\right)$ 


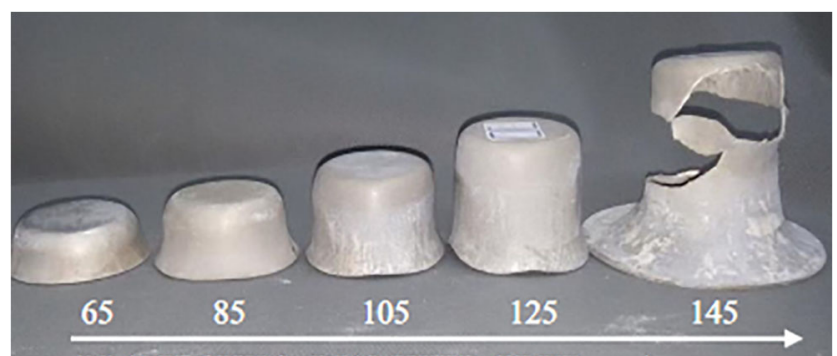

BLANK SIZE in DIAMETER (UNT: $\mathrm{mm}$ )

Fig. 26 Experimental Assessment of Draw Ratios [88]

inhibits material draw in and causes the punch to pierce the material. Too small of a blank size leads to the material being formed without hitting the correct draw depth.

\section{Sharp radii}

It is very difficult to bulge or draw material into a tight internal radius or around a tight external radius (the latter shown in Fig. 24e) without tearing. While some companies solve this by using more advanced forming techniques, it still adds cost and complexity. Because the pressure required to form a component increases in direct proportion with the component's smallest radius, whenever possible, large radii should be used to reduce the required pressure of the hydroforming operation. Depending on the source there are different rules about how sharp a radius can be. Subsequent operations, annealing or pressure intensifiers can help tighten up the radii after the forming operation, but as a general rule keeping radii at least 3 to 5 times larger than the material thickness is advisable whenever possible for high pressure hydroforming operations, [12] and 10 times larger for low pressure operations [4]. That said, more recent work has shown that in certain circumstances the edging technique [89] or a subsequent coining operation can produce radii as small as 2 times the material thickness in certain circumstances (explained in detail in "Advanced hydroforming techniques"section).

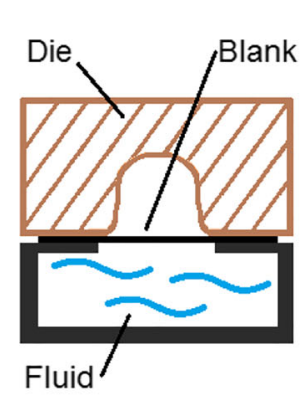

a) Before operation

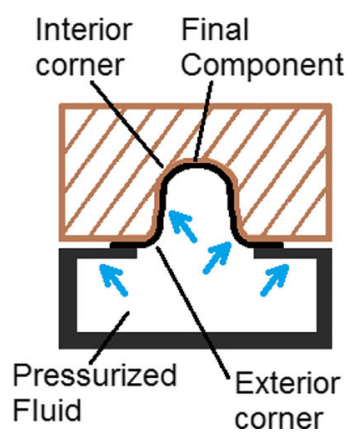

b) Well designed corners

\section{Excessive corner}

thinning and lack of fill

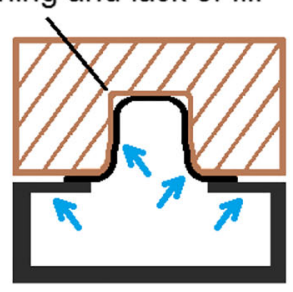

c) Tight interior corner
Inhibited material flow
causing a tear

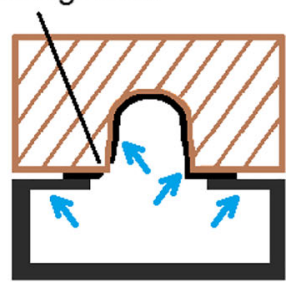

d) Tight exterior corner

Fig. 27 Well designed versus poorly designed interior and exterior corners 




Fig. 28 Rapid feasibility check; reprinted/adapted by permission from Elsevier: Woodhead Publishing [6]

axial feeding is $5.6522^{0.45}-1=1.18$ and without is $2.7183^{0.45}$ $1=0.568$. The reason for this is that the additional material forced in during the axial feeding replaces material which was thinned during the process. From a materials perspective, axial feeding promotes compressive minor strain $\left(\varepsilon_{2}\right)$ which enhances material formability. For a visual understanding of this, the strain path taken is further to the right of the forming limit curve shown back in Fig. 19. The compressive minor strains allow for a higher acceptable level of major tensile strains.

\section{Typical dimensional accuracy and tolerances of sheet and tube}

Thicker and thinner sections are an unintentional by-product of any cold forming process which must be managed. For interior corners wall thinning should be expected in proportion to the sharpness of the corner and the depth of the draw,

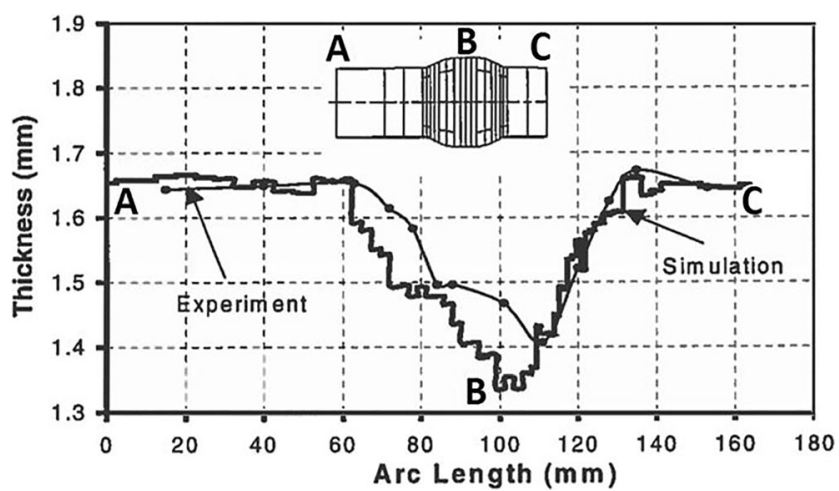

Fig. 29 Wall Thickness variation in an axisymmetric aluminum alloy 6061-T6 THF component with $1.65 \mathrm{~mm}$ initial thickness; reprinted by permission from Elsevier: Journal of Materials Processing Technology [92] i.e. the sharper the corner and deeper the draw, the more the thinning should be expected. This is due to the increased friction that results in stretching material into a tight corner and the additional material required for a deep draw. Counter-intuitively, the material has been reported to actually thicken in certain points during the operation. Generally, this thickening is most pronounced in a tube hydroforming operation (although has been reported in sheet hydroforming as well [90]) where axial feeding is used and is seen on the opposite side of a bulge [91]. Two examples of tube hydroforming thickness distribution can be seen in Figs. 29 and 30.

In these examples the thinning is most pronounced in the areas that are stretched the most and the thickening occurs most in areas where material feeding is present but local material expansion is not.

An example of achievable tolerances during a sheet hydroforming operation with a cavity die was given by Wesselmann et al. (at FF Fluid Forming GmbH) [94]. A customer tasked them with hydroforming a satellite dish with an



Fig. 30 Contours of wall thickness variation in Y shaped THF stainless steel component with $2 \mathrm{~mm}$ initial thickness; reprinted by permission from Elsevier: Materials Science \& Engineering [93] 
Fig. 31 Example of sheet hydroforming tolerances achieved on a Satellite dish (mm) [94]
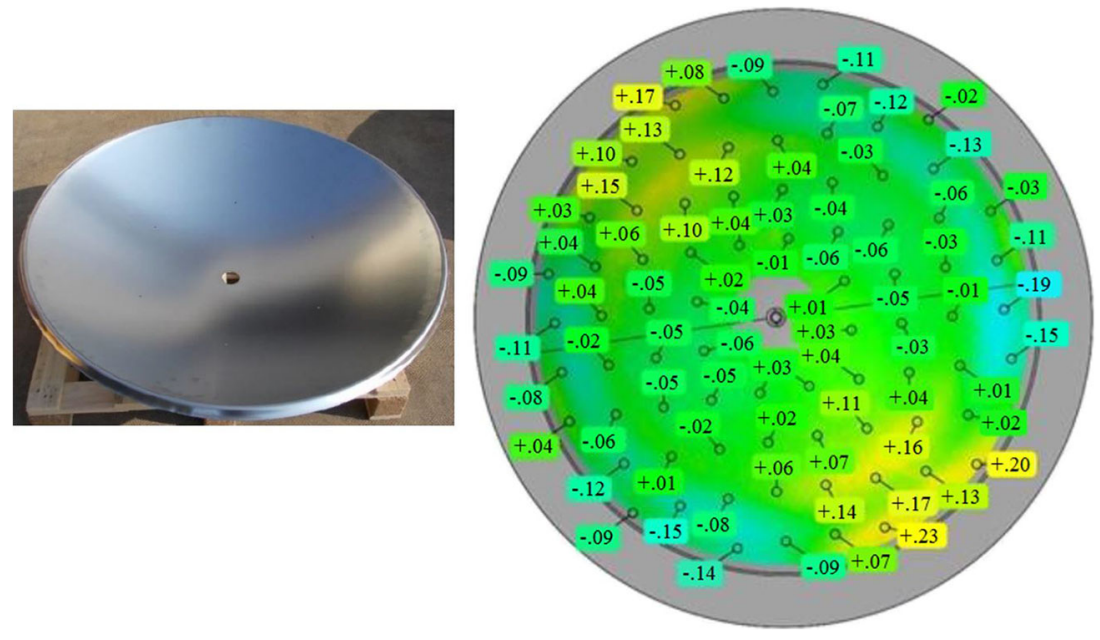

overall tolerance of $\pm 0.5 \mathrm{~mm}$ and after simulation, trials, and geometric measurement they optimized the process to perform the operation with a resulting part within $\pm 0.3 \mathrm{~mm}$ of the nominal value. The satellite dish as well as the tolerance which was measured at multiple locations is seen in Fig. 31.

Tolerances for tube, sheet, and shell hydroforming can vary based upon final component size but suppliers generally quote tolerances of between \pm 0.01 and \pm 0.005 of an inch $( \pm 0.25$ or $\pm 0.125 \mathrm{~mm}$ ). These tolerances are achievable with modern controls which are able to achieve \pm 0.002 of an inch with regard to punch height and $\pm 2 \%$ with regard to fluid pressure [21]. Like all engineering tolerances, tighter tolerances become increasingly difficult to achieve with larger part sizes.

\section{Advanced hydroforming techniques}

This section reviews some of the more advanced techniques used currently in the hydroforming industry. Many different forming techniques have been discovered which aid in the creation of complicated geometries, or add in additional features. Some of the most popular are listed with descriptions, schematics, and governing principles.

\section{Pressure intensifiers}

In cases of insufficient available pressure, pressure intensifiers can be used for finishing operations. They are used as a second step in the hydroforming process [95] and work by enhancing pressure in a given area particularly when a piece of equipment does not have sufficient pressure capacity to create a tight enough radius on its own. A simple example of a pressure intensifier is that of a coining ring which is a large disc that sits on top of the component during a secondary forming operation (although technically the operation bears more resemblance to ironing than coining). A hydroforming operation which produces a part with a large flange radius can be seen in Fig. 32.

A pressure intensifier works by converting the fluid pressure to an acting force concentrated in a corner which is greater than what fluid pressure can achieve alone. This is done by converting the pressure of the fluid exerted on the ring to mechanical pressure which is concentrated into the radius. There are also other kinds of intensifiers that can be used including interior intensifiers that work with cavities and rubber intensifiers. If the example given in Fig. 32 was subjected to a pressure intensifier, the result would sharpen the radius as seen in Fig. 33.

For a radius on the top of the geometry, restriking operations have been suggested in the literature for forming a tighter radius. Also, in a new study Wang et al. suggests using a secondary operation with a counter punch on the opposite side which has a small radius [96].

\section{Multiple stages}

In cases of deep drawing or the creation of finer details in a drawn component, hydroforming operations can use multiple
Fig. 32 Hydroforming operation with inadequate fluid pressure
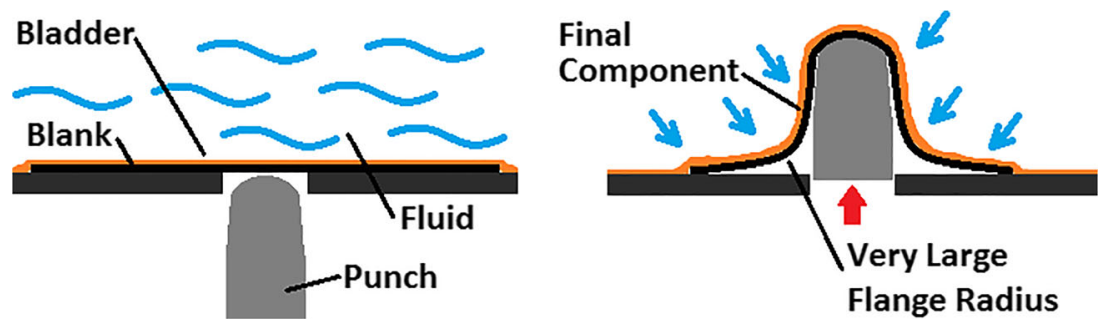
Fig. 33 Pressure intensifier as described in [95]

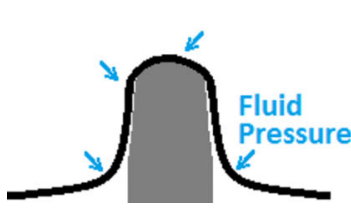

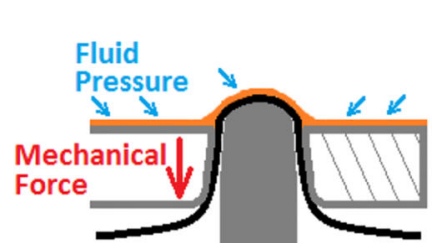

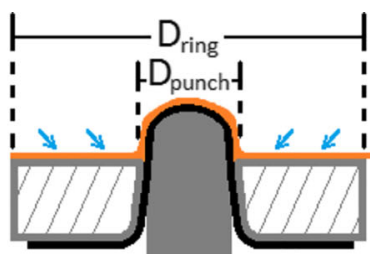

\author{
Ring Area $=A=\pi \frac{D \_r i n g^{2}}{4}-\pi \frac{D \_p u n c h^{2}}{4}$ \\ Mechanical Force $=$ Ring Area $*$ Fluid Pressure
}

sets of dies which change size. In the case of multiple stage deep drawing, shown schematically in Fig. 34, the first punch is larger and deforms more material so that the operation does not exceed the LDR. Then the flange is trimmed off of the part, and it is set over a tube shaped ring. Then the punch is changed to a narrower punch which can make use of the material generated in the first operation and draw it further [21].

\section{In process trimming, cutting \& Hydropiercing}

After a component undergoes a tube hydroforming operation to its final geometry, it can be "hydropierced" which is a process whereby a final component is pierced while still being subjected to internal fluid pressure (Fig. 35). This means that hydropiercing is not a secondary operation as it takes place in situ after the forming operations have completed and while the component is still inside the die. Tube hydroformed components used in automotive applications often make use of holes through which fastening devices are inserted and in such cases hydropiercing can be a cost effective alternative to drilling, milling, cutting or mechanical punching [6]. When hydropiercing care should be given as to what happens to the punched material and how it is removed or bent. While this technology may theoretically be possible with a bladderless sheet hydroforming process, the examples in the literature are limited to hydropiercing of tube hydroformed components.

In a cavity sheet hydroforming process, dies can be designed in such a way as to shear components after the forming operation has completed which removes the need for subsequent cutting or shearing operations [20]. A sharp edge is created in the die whereby when the forming operation completes, the pressure builds around a sharp edge, and the formed metal is forced over which shears the component in situ as shown in the industrial example from Quintus Technologies (Fig. 36).

\section{Predrilled hole applications}

There are a few different ways in which drilling holes in the blank prior to the forming operation can be beneficial to creating more complicated geometries or enhancing physical characteristics such as stiffness. If a hole is drilled into a component before a pressing or hydroforming operation, then the material can be pulled into the hole to create a circular protrusion [21]. Hole flanges are a common sheet forming operation and are "used for appearance, rigidity, hidden joints, and strengthening the edge of sheet metal parts" [97]. Also, predrilling a hole prior to a forming operation is a punch hydroforming (and deep drawing) technique that can allow for less material thinning in a wall by allowing material to flow into the wall from both the top and flange sections. However, it is generally only useful when the thickness in the walls is important and the top of the geometry is to be removed after the operation. Lastly, this process is only viable in deep drawing or with hydroforming equipment that has a bladder. If there is fluid acting directly on the blank, the fluid will likely find a path through the hole. This process is shown in (Fig. 37).

\section{Expansion forming}

One technique developed for manufacturing tube components in a hydroforming machine is known as "expansion forming".

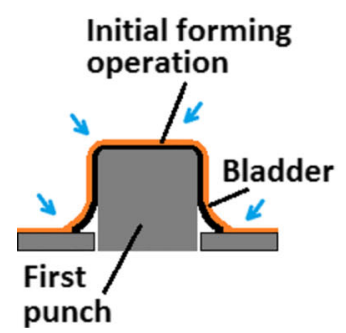

a) First stage

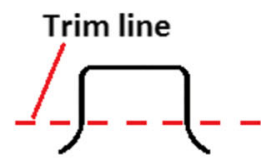

b) Trim part

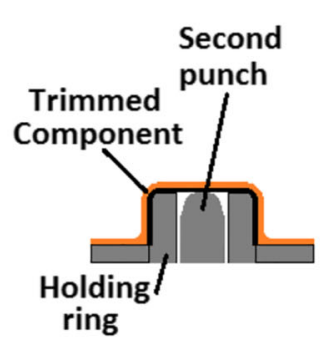

c) Tool change



d) Second stage

e) Final part

Fig. 34 Hydroforming using a holding ring and multiple stages [21] 




Fig. 35 Various types of hydropiercing; redrawn from [6]

This technique utilizes a fluid cell press with a specially made tube die inside. A tube is inserted into the die and rubber is fitted inside the tube. Upon initiation of the pressure cycle, the fluid pressure will push the rubber inside of the tube outwards, expanding it into the die and creating a tube hydroformed component on sheet hydroforming equipment. The dies used generally have to be split dies which increases labor costs and cycle times and axial feeding is generally not possible but this is a proven way to form tube components on SHF equipment, [20] (Fig. 38).

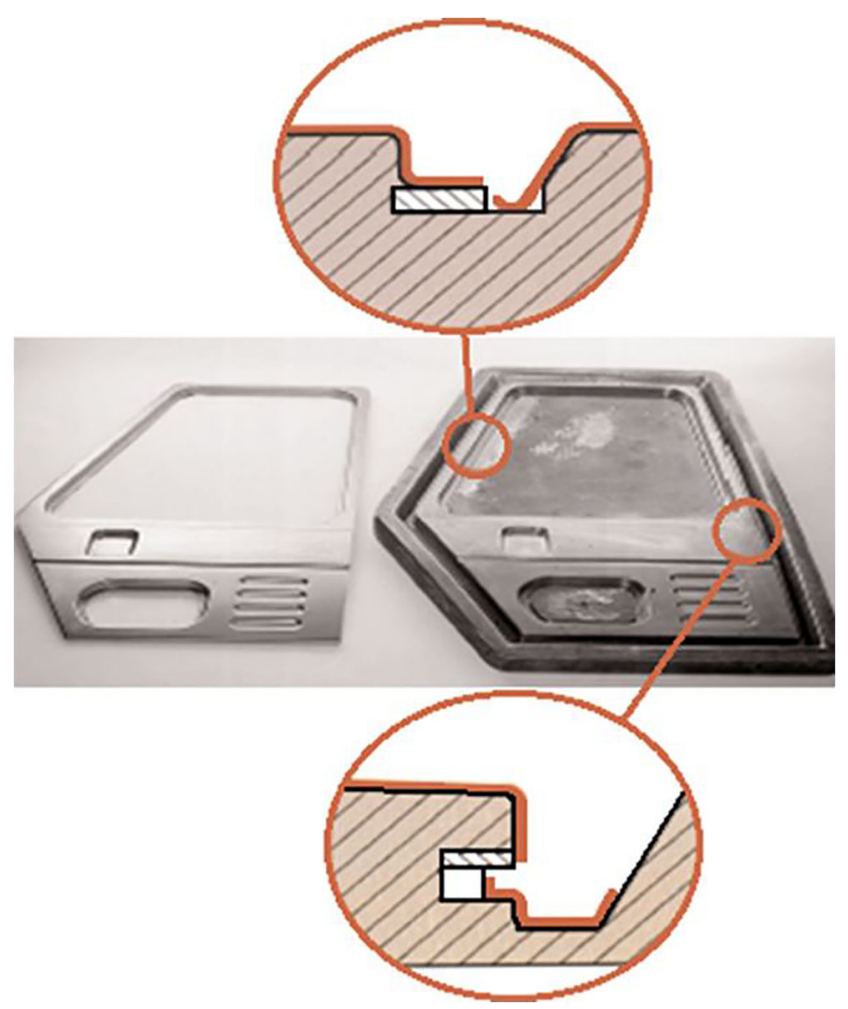

Fig. 36 In process trimming; republished with permission from [20]
Edging

An alternate technique to the coining operation described earlier in 5.3.1 is to increase the position of the punch higher than necessary and then back it down to the final position at the end of the operation while always maintaining high fluid pressure. This technique, as described by Triform presses (an equipment vendor) is called edging and allows for extra material to stretch in from the flange on the upwards stroke and be pushed into the corner when the punch travels back down. Bell et al. showed that a flange radius could be reduced significantly by using the edging process and provided an empirically derived equation for calculating flange radii [89]. Edging, unlike a coining operation, does not require extra tooling or an additional forming cycle but it is not quite as accurate or repeatable. If the tolerance on the radius is critical, a coining operation is preferred, but if it not then a punch hydroforming operation with an edging step at the end is likely acceptable [21] (Fig. 39).

\section{Hydroforming process automation}

In related sheet metal forming processes, equipment manufacturers have invested heavily in automation in order to reduce cycle times. Schuler, a press manufacturer, have incorporated many servo presses together to accommodate more complicated operations which optimize transfer taking into movement overlaps. This new technology can produce up to 100 car body parts per minute which is nearly twice as fast as conventional lines [98]. AIDA, another press manufacturer, has also adopted servo drive systems in conjunction with new transfer presses to increase efficiency. Because of the increasing amount of electrification and hybridization of modern vehicles, sheet metal components are increasingly in demand and require increasing levels of complexity. Therefore AIDA have aimed to combine many presses into one system to ensure that future systems are versatile.

Hydroforming operations are also likely to follow the same trend of increasing automation, but because the technology is newer and more complicated it has a more stringent set of challenges. However, there are developments in efficiency aimed at reducing cycle times by increasing machine utilization with press automation. For example, Borit $\mathrm{NV}$, a metal forming company based in Belgium, has developed an advanced process called Hydrogate ${ }^{\mathrm{TM}}$ which is based on hydroforming and allows an automated material feed which feeds material from rolled sheets automatically. This significantly reduces cycle time and increases output [99] (Fig. 40).

\section{Hybrid Pressing \& Hydroforming}

Certain sheet hydroforming technologies utilize both traditional pressing and hydroforming actions to form sheet. As 



Fig. 37 Expansion hole drilled in the top of a blank

seen in Fig. 41, a deep drawing operation can be combined with a hydroforming operation to bulge a sheet metal component in multiple directions in the same machine.

\section{Hybrid double blank hydroforming}

The use of two blanks during a hybrid hydroforming operation is also possible. This allows for the press to essentially double its productivity, but can usually only be applied to two geometries which can be formed with the same pressure cycle and blank holding force (however [100] looked at using counter pressure on one blank to compensate). The operation shown would be a hybrid dual sheet hydroforming process and would work by first pressing both sheets and then pumping fluid in between them while the punch backs off. This is depicted schematically in Fig. 42.

\section{Micro hydroforming}

Micro manufacturing is a promising research area with a large amount of commercial potential due to an increasing demand in telecom, electronics and medical device sectors [43]. In hydroforming, there are many different research areas looking into both sheet and tube hydroforming applications. While the same principles apply, there are challenges which are inherent to micro manufacturing that are not present in similar macro sized applications. In general, the main challenges to micro manufacturing are cost, accuracy, precision, and standardization. [101] These challenges stem from a number of different technical concerns, for example in industrial forming operations, grain sizes are generally considered small and homogenous but with micro manufacturing grains can be considered anisotropic which adds complexity to forming operations as shown in Fig. 43. Anisotropy causes variation in material properties depending on orientation which is shown most frequently in the literature as mechanical property changes with regard to rolling direction. At the macro scale this can lead to typical values like a $5.5 \%$ difference in yield strength depending on orientation [89] which could impact forming and on the micro scale these differences are more pronounced. Other technical concerns include: extreme tribological conditions caused by high surface to volume ratios, achieving tolerances [102], inapplicability of available lubrication products, excessive forces on miniature dies, and handling concerns, [103].

To address these manufacturing challenges, many streams of research are underway at various academic and private institutions. Some of the research areas are based upon new techniques or hardware, for example, Sato et al. improved the accuracy of drawing titanium, bronze and stainless steel micro cups by utilizing a servo drive in a micro SHF operation [104]. Sato et al. concluded that adding counter pressure can improve formability [105]. Ngaile and Lowrie [103] introduced a new hydroforming system with a floating die assembly to improve sealing by decoupling the sealing and material feed requirements and verified the invention on stainless steel tubes. Nakamori et al. designed a highly accurate contact sensor which was built into the die to improve the accuracy the bulged section in a THF operation which created a Y shaped component [106].

Furthermore, other researchers are performing work that addresses identifying the key process variables in different operations and how they interact with one another. A better understanding of the key process variables Manabe et al. performed a study on $\mathrm{T}$ and cross shaped micro tubes to determine what the most influential factors in the micro forming process for these shapes were and concluded that they were: lubrication condition, material property, formed shape and grain size [107]. In SHF, Liang et al. studied how the
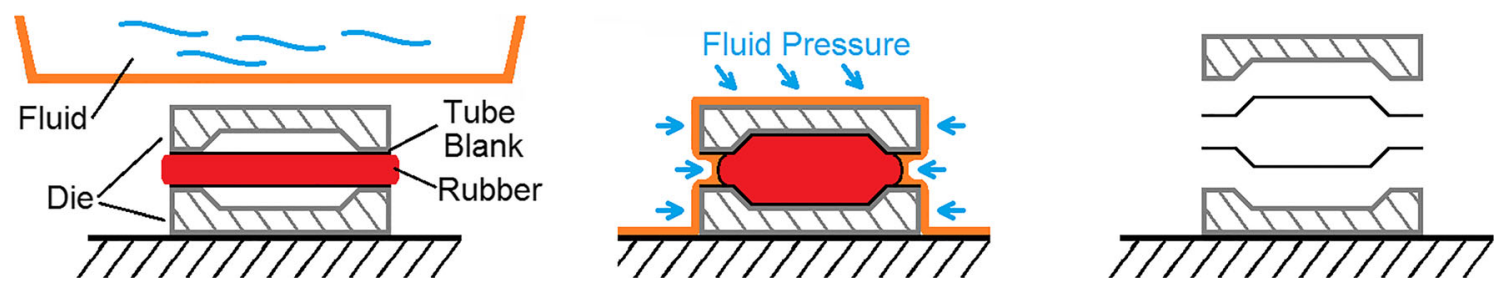

Fig. 38 Expansion forming schematic; redrawn from [20] 


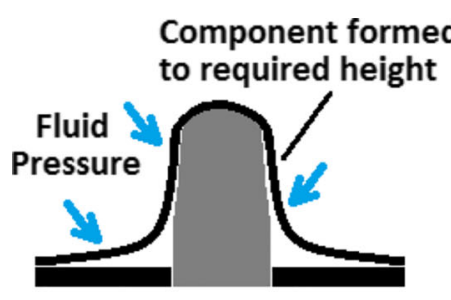

a) Punch first reaches maximum
required height

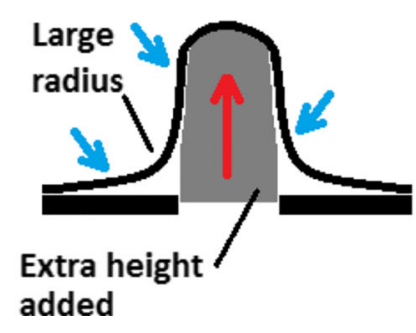

b) Additional height added to punch

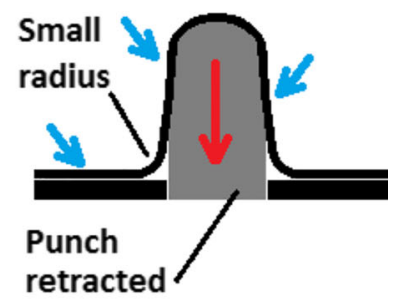

c) Punch height reduced with high fluid pressure maintained

Fig. 39 Sheet Hydroforming with an edging operation used to tighten a flange radius

hydraulic pressure in micro hydromechanical deep drawing effects wrinkling and earing and determined that "ultra-high" pressure can avoid wrinkling [108].

In order for micro hydroforming to overcome the aforementioned challenges these advances need to continue in conjunction with other supporting manufacturing technologies. Process parameters need to be further investigated with emphasis on the interactions between key process variables to ascertain a better understanding of the process and how to design for hydroforming operations. New tooling innovations are needed to provide sufficient force to seal while not harming the die [103]. New lubrication methods need to be developed which work well and repeatably on the micro scale.

The development of supporting technologies could also be crucial in the development of micro hydroforming as they could ensure commercial viability of end products. For example, in T shaped THF operations with axial feeding there is generally an increase in wall thickness on the non-T side [91]. In macro hydroforming this is usually evenly distributed and not of any major concern, but with micro THF it is more of an issue because of the higher friction due to the close proximity of the fluid to the walls and the relatively large walls as compared to the diameter of the tube. This juxtaposition in wall thickness can be seen in Figs. 44 and 45 where the tube walls are about $10 \%$ of the outside diameter [91] whereas with the micro tube, the walls comprise roughly $40-50 \%$ of outside diameter [107]. Micro machining could help ensure the micro tube is fit for purpose by removing the aforementioned protrusion and possibly skimming the walls to reduce friction, but only if the micro machining technology is compatible. Furthermore, punches used for axial feed often have a hole drilled in the middle for fluid to travel through to pressurize the tube during forming. This can be an issue if the punch has a small diameter and a comparatively long length [103].

\section{Warm hydroforming}

Warm, hot and isothermal forming and forging techniques have been used for millennia as a way to increase the formability by increasing the amount of strain a material can undergo before fracture by applying heat. Even though the potential benefits are significant, it has not been widely incorporated into the hydroforming industry because of the technical challenges, the first of which is forming with warm metal adjacent to fluids, oils, and rubbers [109] which generally are not able to withstand high temperature applications. To solve this problem researchers have tried using, oils [110], gasses [111] or even steam [112] can which have a higher operating temperature than water. Additionally, clever placement techniques can be utilized which heat parts of the blank which are not adjacent to the fluids (like the flange area in SHF). This technique was found to be optimal by Acar et al. for warm sheet hydroforming of AA5754-O in a punch hydroforming operation [113]. Thermal conductivity for
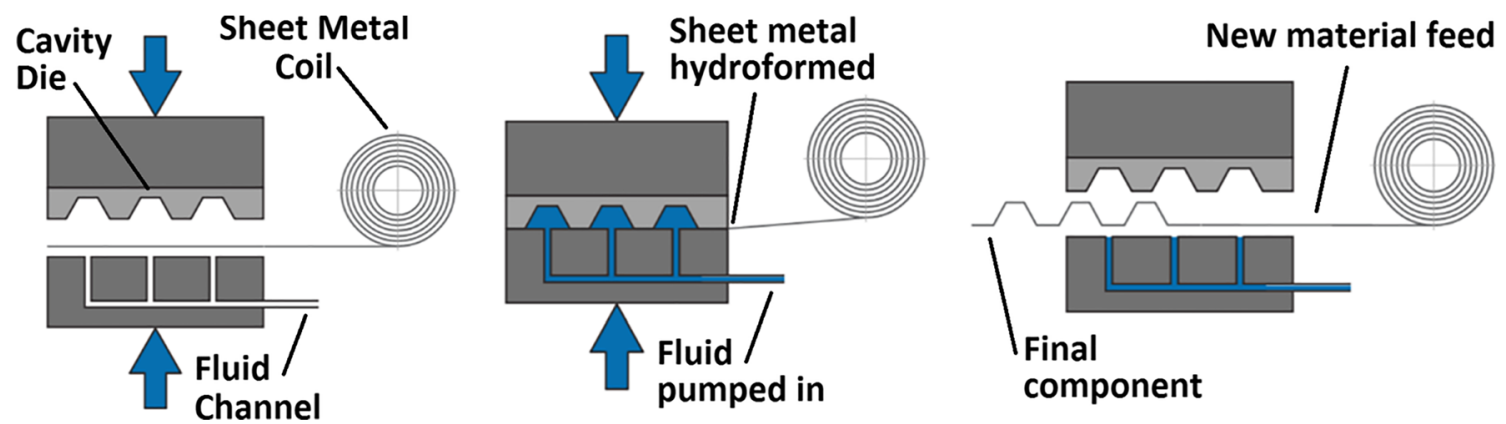

Fig. 40 Automated SHF schematic [99] 


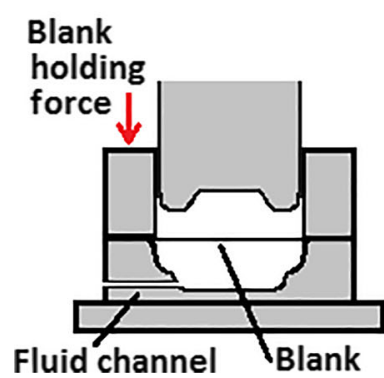

Fig. 41 Dual process mechanical pressing with hydroforming; redrawn from [38]


warm operations must also be taken into account. The thermal conductivity of tool steel is far higher than that of the fluids or rubber used, so it is likely that the blank will more closely align to the temperature of any tooling that it is touching instead of the fluid or rubber. This bears particular significance with punch and cavity hydroforming, as with punch hydroforming the blank will emulate the temperature of the punch, and with cavity hydroforming the temperature will be much closer to the fluid. Other challenges have to deal with the handling of hot fluid or gas at high pressure, the preheating and handling of specimen at elevated temperature, chemical reactions at high temperatures, and cost constraints such as cycle times, which while higher than cold hydroforming, are still lower than superplastic forming [5].

Regardless of these difficulties the potential is so great that research on warm hydroforming is being carried out in many areas. Texts have been written reviewing warm hydroforming challenges and potential such as Landgrebe et al. who wrote about the potential of warm tube hydroforming as it relates to the automotive industry [111]. Gao et al. used a warm sheet hydroforming operation using viscous fluid on a magnesium alloy (AZ31B) showing that the formability is best for their operation at $200{ }^{\circ} \mathrm{C}$ [114]. Aissa et al. proved the concept of using steam to during a warm hydroforming operation [112]. Türköz et al. looked at the optimal radii in sheet hydroforming used on the punch and the flange radius as they relate to warm hydroforming [115]. Each fluid has different advantages in the hydroforming process. Water based fluids are cheap but need anti-microbial agents added [6] and have a low working temperature before turning to steam. This means the forming operation either needs to be modest in heat application or cleverly designed to separate the fluid from hot surfaces (as in Fig. 47, see Table 1) so that fluids interact only with the cooler parts of the blank. Hot gasses must be specifically chosen to not interact chemically with surfaces but as the chemical inertness of a gas increases there is a corresponding price increase (e.g. air, nitrogen, argon). Smart fluids show promise but are in the early stages of development and carry a host of technical challenges and understanding required [116] and ceramic beads are not technically a fluid so hydrostatic pressure is not guaranteed and forces are transmitted through "force chains" [117]. In addition, the medium can have wear issues as ceramic beads break down after use.

\section{Development directions}

There are many different ways in which hydroforming research is progressing and a lengthy description of some of the more relevant technologies including schematics can be found in texts such as [1], [109, 118] but to quickly summarize some of the main components the following table is presented. This shows each technology followed by a newly developed hierarchy shown in Fig. 46 stating where each technology fits under the original subcategories in first listed in Fig. 1. Some of the various technologies such as warm hydroforming appear in multiple locations as they are applicable in multiple technological areas.

All of the research areas presented below are being explored to either enhance the formability of a hydroforming
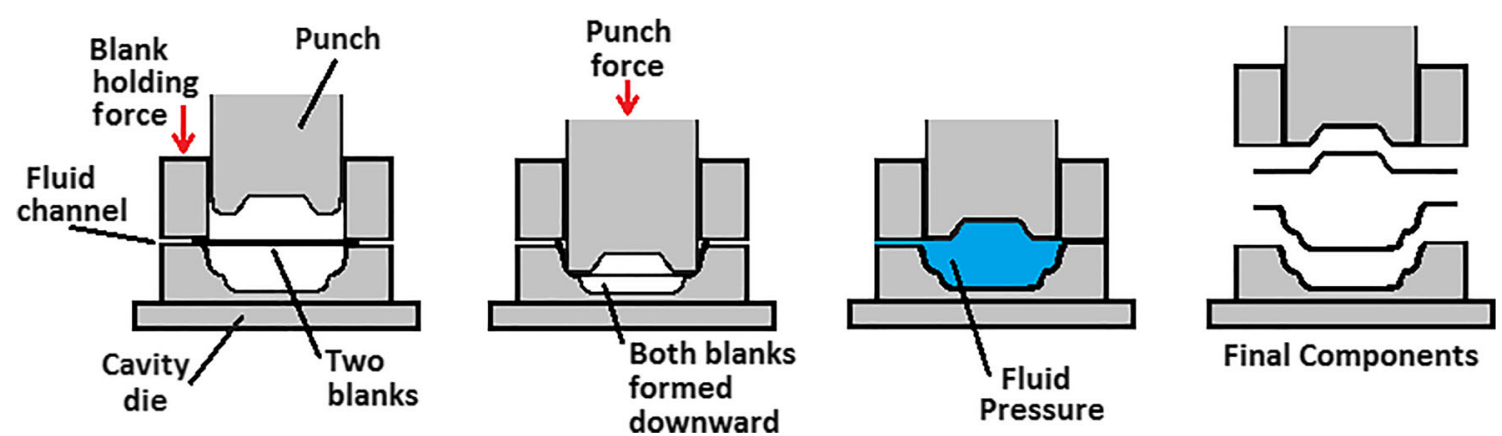

Fig. 42 Double blank sheet hydroforming; redrawn from [38] 
Fig. 43 Morphology of hydroformed grains at macro and micro scales

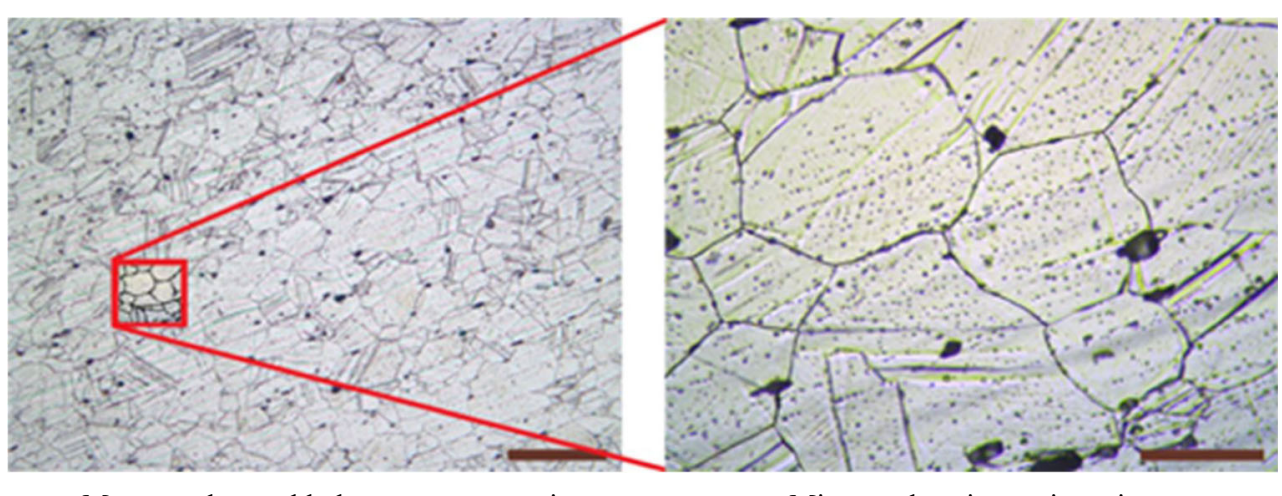

Macro scale roughly homogeneous grains

Micro scale anisotropic grains process or reduce the costs of the process. Each technology is briefly summarized in Table 1 alongside a schematic and brief description of each process. Using the criteria described by Mankins [119] the following "Technology Readiness Levels" (TRL) are derived and shown with a score of 1 equating to purely theoretical technology and 9 being completely proven technology. Technology readiness levels were developed by NASA as a way to of concisely describing and comparing how mature a technology is based on its ability to be deployed in a commercial application.

Now this paper will revisit the main three categories of hydroforming which have been described at length in the literature and are defined in Fig. 1. To this original structure, all of the aforementioned technologies will be added. The resulting taxonomy will show where all of the technologies fit in one single diagram and point out which ones are currently used commercially as well as which are not yet commercially available due to either technological or economic rationale. Figure 46 contains all of the varieties of hydroforming described in the previous sections, but not the simpler hydroforming tricks (such as edging) as they do not qualify as independent technological branches. This diagram represents a current snapshot of the possibilities in hydroforming technology.

All of the technologies which are in development can also be ranked by their technology readiness level which allows for a roadmap towards future hydroforming capacity. This gives a

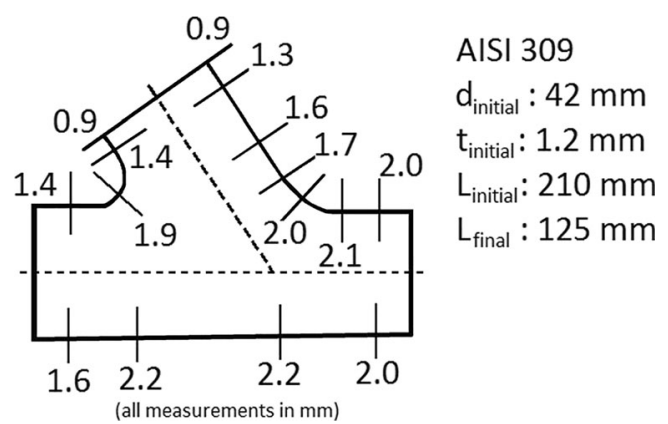

Fig. 44 Thickness of Y shaped automotive exhaust component (Redrawn from [91], as seen in [6]) categorization of the relative maturity of the experimental hydroforming technologies discussed above as well as an indication of when they will be commercially viable. This roadmap of hydroforming technologies defined in Table 1 can be seen in Fig. 47.

A few other novel technologies which are either periphery operations or hydroforming adaptions which deserved mentioned as well include the following. Many contributions have been written on using additively manufactured dies including a book edited by Brandt [153] which contains an extensive chapter written by Hölker-Jäger \& Tekkaya [154] on the process. Similarly others are developing other die materials such as Kleiner et al. [155] who discuss "ultra high performance" concrete dies for SHF operations. Wang et al. [156] used a hydroforming process that had been adapted to form large rings of rolled sheet metal. Numerous hybrid processes are mentioned in the literature including Geiger et al. [157] who create a complicated geometry by welding together a boxed section from two sheets and a tube, and forming it in a single hybrid tube-sheet hydroforming operation. Werner et al. [158] describe the use of CNC bending to get metal

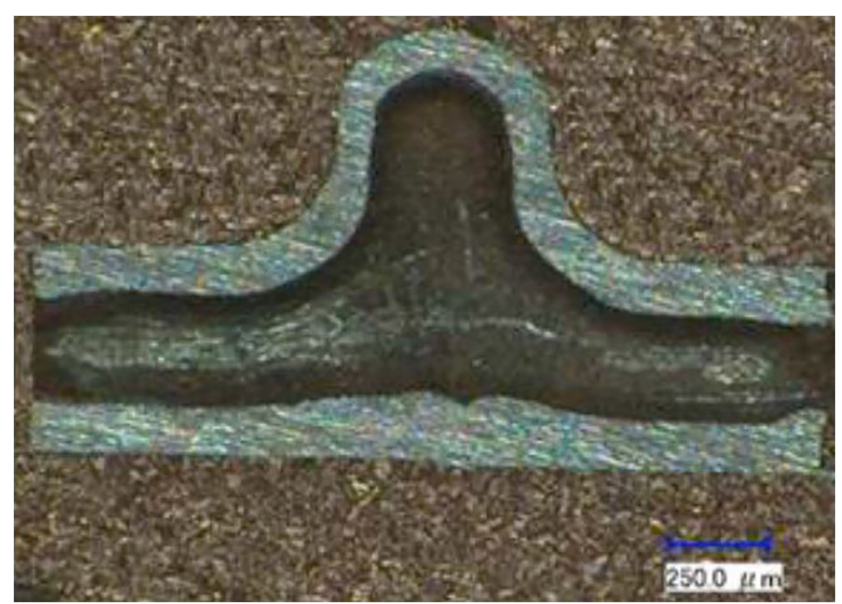

Fig. 45 Cross section of a micro THF tube; reprinted by permission (C) 2017 under (CC BY NC ND) from [107] 
Table 1 Hydroforming Research Area Schematics

\begin{tabular}{|c|c|c|}
\hline Technology & Description and Technological Maturity & Schematic \\
\hline $\begin{array}{l}\text { Hybrid } \\
\text { Injection } \\
\text { Molding and } \\
\text { Hydroforming }\end{array}$ & $\begin{array}{l}\text { Hybrid injection molding and hydroforming } \\
\text { enables the creation of complicated shapes } \\
\text { by using a THF process and then injection } \\
\text { molding plastic around the resulting part } \\
\text { while it is still in the die [118]. The } \\
\text { publications in this area showcase many } \\
\text { automotive applications [120]. } \\
\text { TRL: } 8\end{array}$ & $\begin{array}{l}\text { Hydroformed } \\
\text { Injection } \\
\text { molded plastic } \\
\text { Hydroformed tube with injection molded } \\
\text { plastic on the exterior; reprinted by permission from } \\
\text { [118] (c) } 2016\end{array}$ \\
\hline $\begin{array}{l}\text { Moveable Die } \\
\text { or } \\
\text { Counterpunch }\end{array}$ & $\begin{array}{l}\text { Having a moveable die (or counterpunch) } \\
\text { that supports the material while it is moving } \\
\text { can increase friction in areas preventing } \\
\text { premature fracture and enhancing } \\
\text { formability. This technology is already } \\
\text { available from some suppliers (especially in } \\
\text { the THF industry), but there is still ongoing } \\
\text { research [75]. } \\
\text { TRL: } 8\end{array}$ & Fluid 1 Fluid pressure \\
\hline $\begin{array}{l}\text { Hot Gas/ } \\
\text { warm } \\
\text { Hydroforming }\end{array}$ & $\begin{array}{l}\text { This technique uses hot gas, warmed fluid, } \\
\text { steam, or conductive heat and has a lot of } \\
\text { potential to increase material formability } \\
{[112] \text {. Many experimental studies have been }} \\
\text { published including Koc [6], who showed } \\
\text { hydroformed box and cup sections Takata et } \\
\text { al. [121], who used sheet applications on Al- } \\
\text { Mg sheet Yuan et al. [110] who formed } \\
\text { magnesium alloy tube with hot oil, and } \\
\text { Landgrebe \& Schieck [111] who used hot } \\
\text { gas hydroforming to create automotive } \\
\text { components. Maeno et al. bulge an } \\
\text { aluminum tube without controlling internal } \\
\text { pressure by using resistance heating [122]. } \\
\text { In a similar work, Maeno et al. use } \\
\text { resistance heating on a steel tube during a } \\
\text { forming operation which was developed so } \\
\text { that a subsequent heat treatment could be } \\
\text { omitted. Türköz et al. [123] explain the } \\
\text { complete fabrication and testing of a warm } \\
\text { hydroforming system. } \\
\text { TRL: } 7 \text { [124] }\end{array}$ & Warm hydroforming schematic \\
\hline
\end{tabular}


Table 1 (continued)

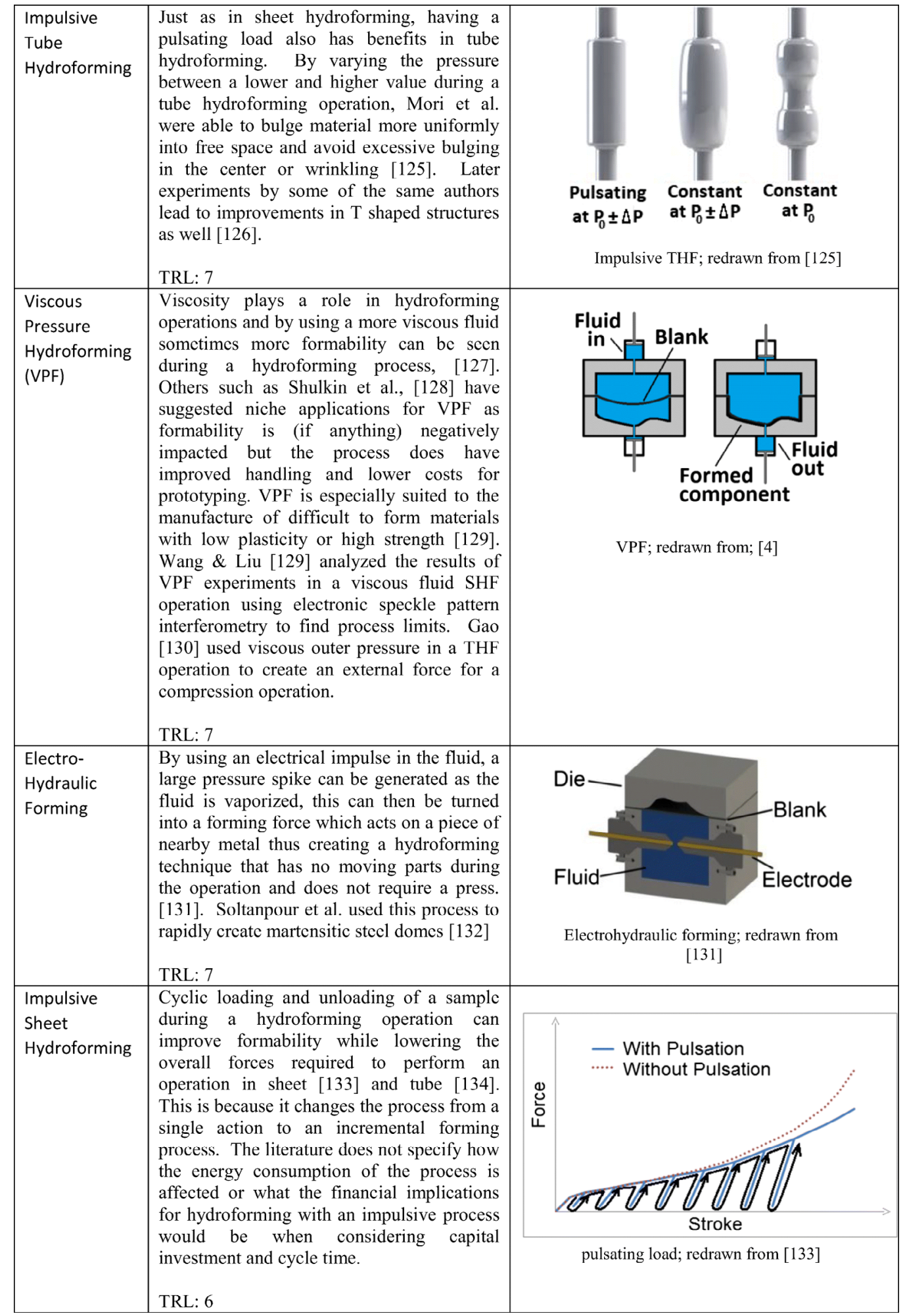


Table 1 (continued)

\begin{tabular}{|c|c|c|}
\hline $\begin{array}{l}\text { Multi-stage } \\
\text { Hydroforming }\end{array}$ & $\begin{array}{l}\text { By first forming the blank in the opposite } \\
\text { direction of a deep draw hydroforming } \\
\text { direction, more material can be pulled in } \\
\text { from the flange allowing a deeper draw } \\
\text { [131] with less thinning and less wrinkling } \\
\text { [135]. While this phenomena is well known, } \\
\text { more work is underway regarding the best } \\
\text { ways of multiple stages in sheet [136] and } \\
\text { tube hydroforming [137] applications. } \\
\text { TRL: } 6\end{array}$ & $\begin{array}{lc}\text { Pressure } \\
\text { increased }\end{array}$ \\
\hline $\begin{array}{l}\text { Tube } \\
\text { Expansion } \\
\text { Using Gas } \\
\text { Detonation }\end{array}$ & $\begin{array}{l}\text { In a "technically comparable procedure" to } \\
\text { hydroforming, gas detonation is used inside } \\
\text { a tube to perform a high strain rate explosive } \\
\text { forming operation [138]. This is done by } \\
\text { filling the chamber with gas (in one case } \\
\text { hydrogen and oxygen [139]) and explosively } \\
\text { forming the part. This does not require a } \\
\text { press as the dies are "inertia locked" in } \\
\text { position. } \\
\text { TRL: } 6\end{array}$ & $\begin{array}{l}\text { Gas detonation; reprinted by permission } \\
\text { from Springer Nature: Production Engineering [139] }\end{array}$ \\
\hline $\begin{array}{l}\text { Micro } \\
\text { Hydroforming }\end{array}$ & $\begin{array}{l}\text { Studies are being carried out by many } \\
\text { researchers in the area of micro } \\
\text { hydroforming. Although this area has } \\
\text { numerous challenges, the demand for } \\
\text { capability is large from the telecom, } \\
\text { electronics and medical device sectors [44]. } \\
\text { TRL: } 6\end{array}$ & $\begin{array}{cc}\text { MDD }-\frac{1}{7} & 500 \mu \mathrm{m} \\
\text { Micro SHF; } & \text { Micro THF; } \\
\text { Reprinted by permission } & \text { reprinted by permission } \\
\text { from Elsevier: Journal of } & \text { under (CC BY NC ND) } \\
\text { Materials Processing } & \text { from [107] C } 2017 \\
\text { Technology [104] } & \end{array}$ \\
\hline $\begin{array}{l}\text { Hydro-rim } \\
\text { deep drawing }\end{array}$ & $\begin{array}{l}\text { This technique uses pressure on the back } \\
\text { side of the flange during the forming } \\
\text { operation to force fluid into gaps in the } \\
\text { flange and allows more material to flow into } \\
\text { the working zone. According to the relevant } \\
\text { literature this can improve the limit draw } \\
\text { ratio [140] significantly by increasing } \\
\text { material feed and decreasing friction [141]. } \\
\text { Recent experiments by Khademi et al. have } \\
\text { shown that radial and cavity pressure had a } \\
\text { significant impact on the creation or } \\
\text { prevention of wrinkling in the side wall due } \\
\text { to the impact of higher compressive stresses } \\
\text { from the imposed radial pressure [142]. } \\
\text { TRL: } 5\end{array}$ & Hydro-rim deep drawing; redrawn from \\
\hline
\end{tabular}


Table 1 (continued)

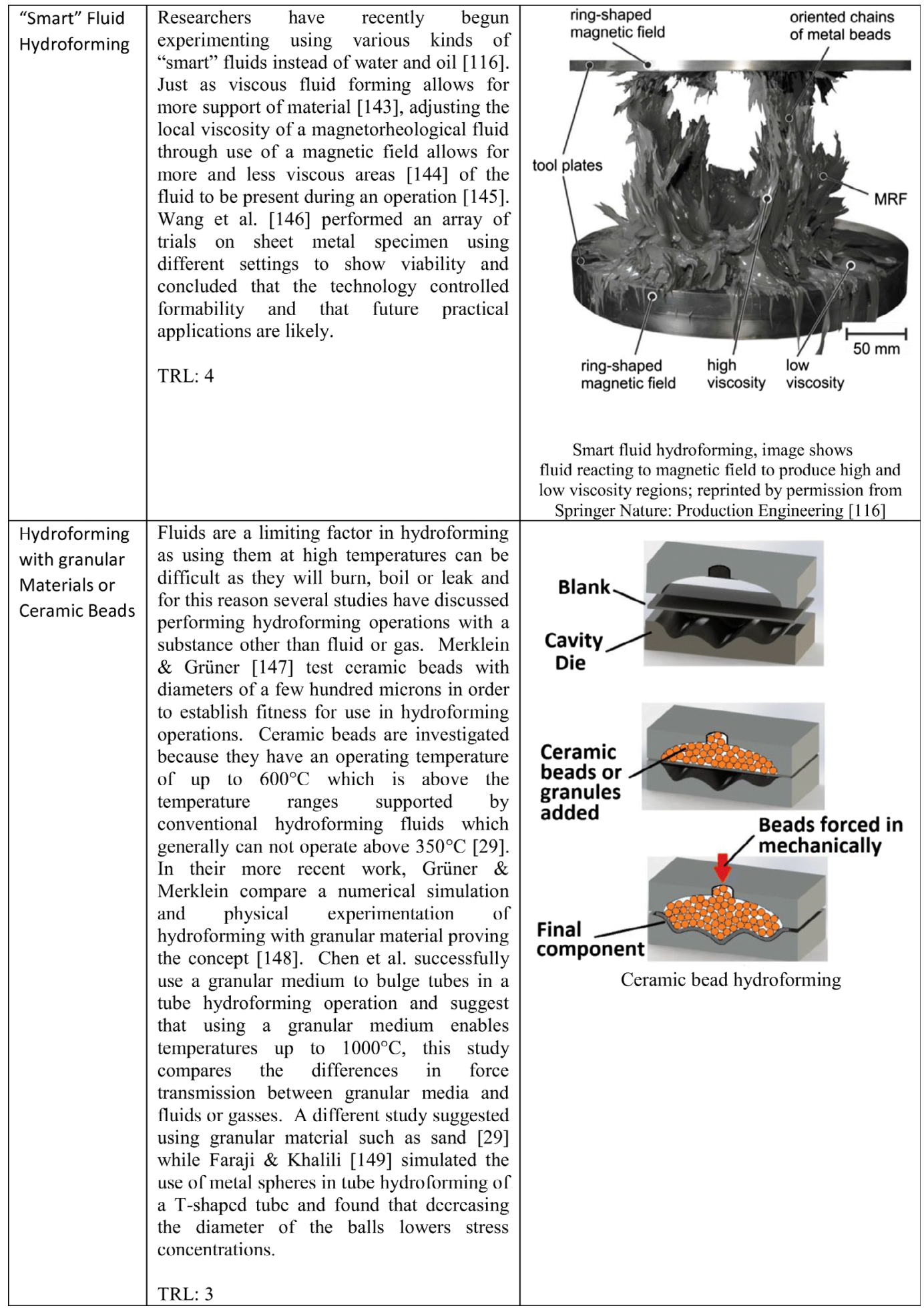


Table 1 (continued)

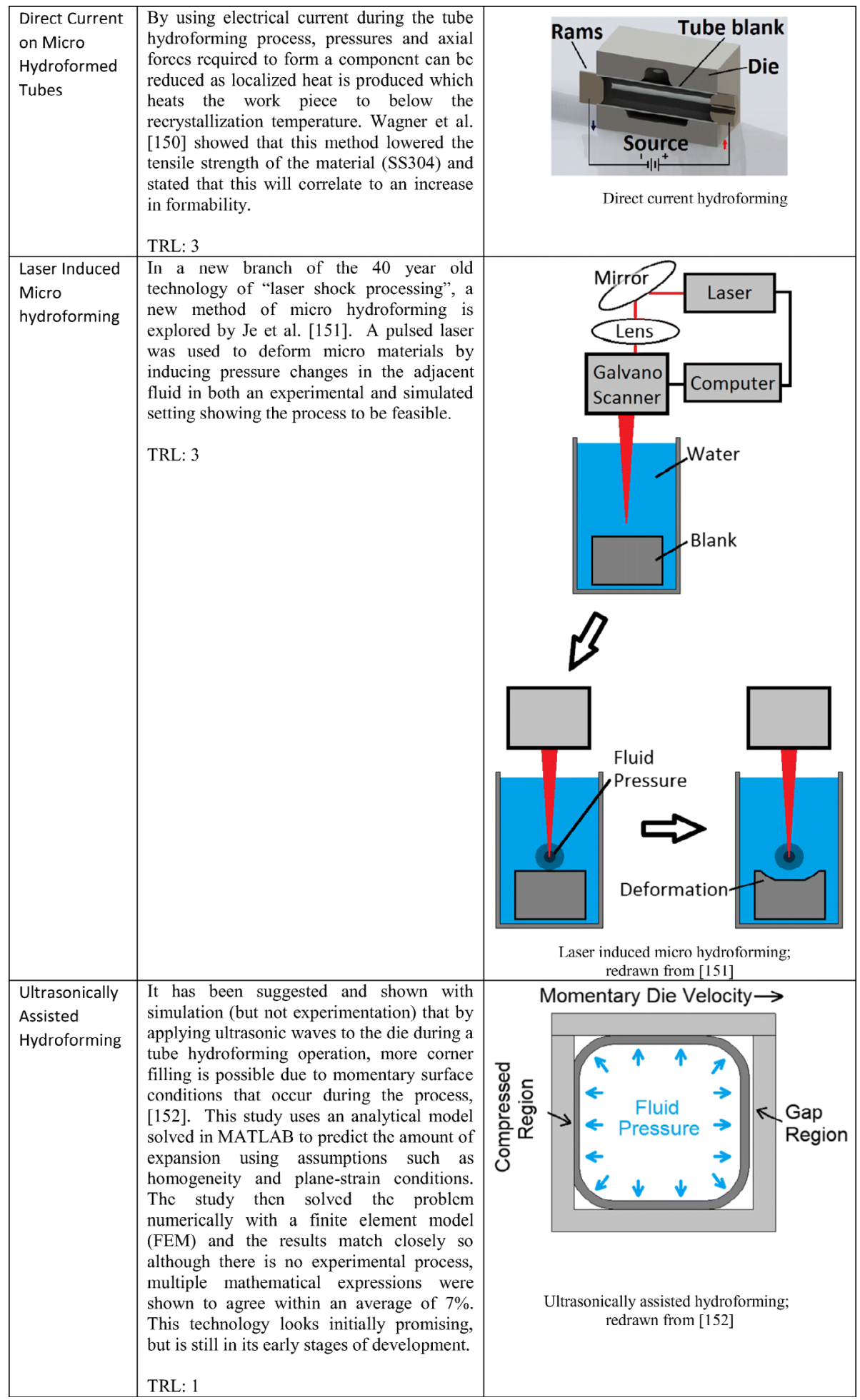




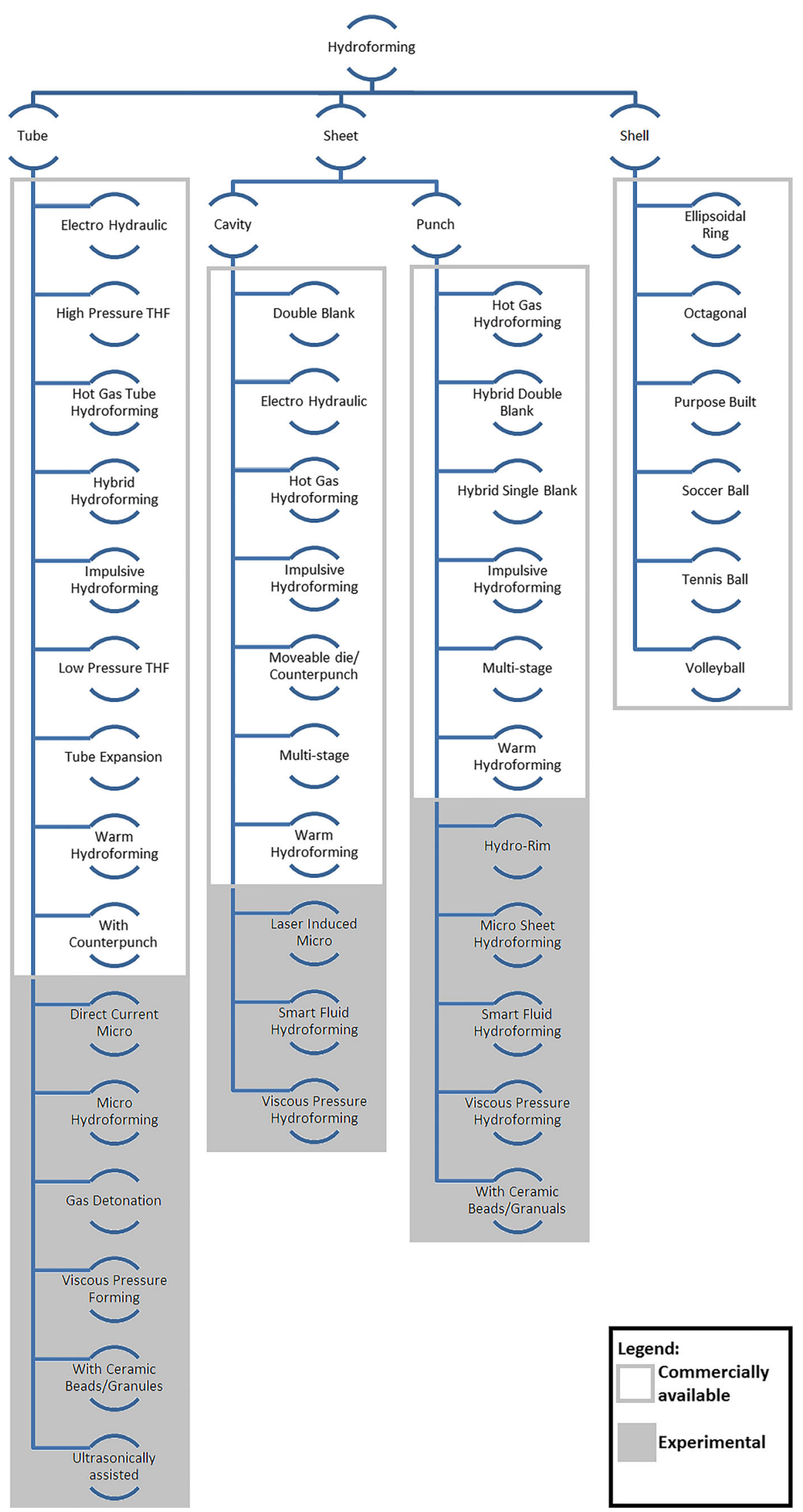

Fig. 46 Taxonomy of hydroforming technologies 
Fig. 47 Roadmap of future of hydroforming technologies

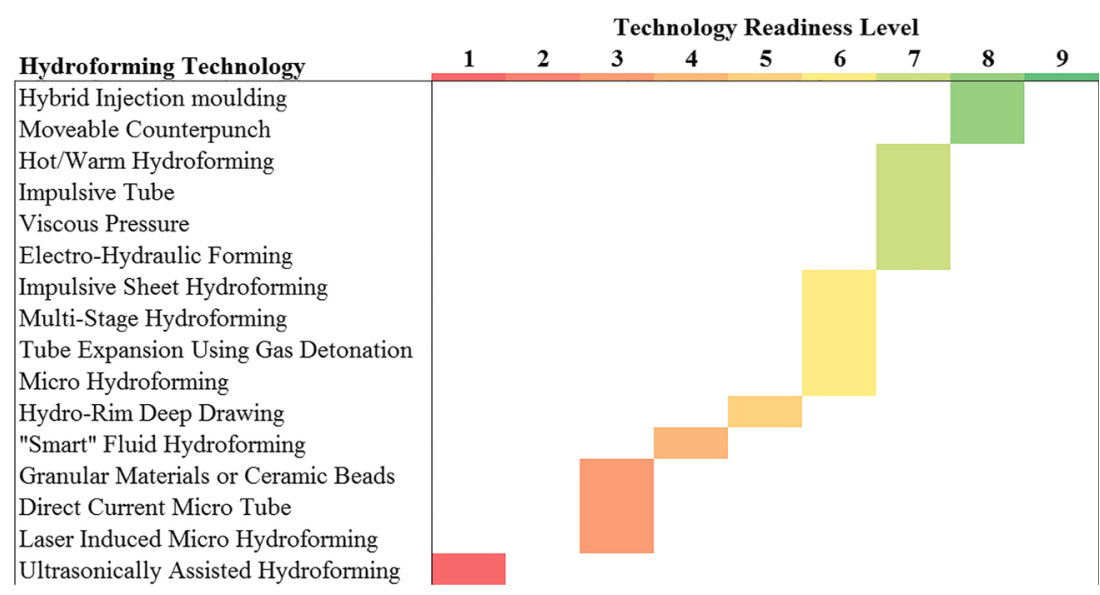

blanks into an appropriate shape before the hydroforming operation. Also described by Werner et al. [158] is a technique for using pulsed magnetic fields to create tailor welded blanks for use in hydroforming. Psyk et al. [159] used a similar technique for joining dissimilar tubes before a hydroforming process. The pulsed magnetic fields which weld the blanks together are created at lower temperatures than traditional welds would be able to use thus reducing the influence high temperature welding has on the final material properties [158].

Other sustaining developments which enhance the hydroforming process include: enhanced systems to prevent leakage [160], better ways to utilize material feeding with moving dies and special axial feeding motion allowing for larger cross sectional expansion [161]. Halkaci et al. [162] experimented with using a shallow draw bead to increase the limit draw ratio by increasing strain hardening in the flange area. Also Sato et al. [163] successfully used a servo system in their micro hydroforming of $0.8 \mathrm{~mm}$ diameter circular cups to generate high dimensional accuracy and prevent wrinkles.

\section{Discussion}

\section{Advantages and disadvantages of hydroforming}

Hydroforming has many advantages over competing manufacturing processes as well as a few disadvantages all of which will now be discussed and summarized in Table 2 . The first of these is an increased formability which can be most clearly seen in the literature as an increased limit draw ratio from 2.2 to 2.8 [3]. From a manufacturing perspective, this means that more complicated geometries can be created during a hydroforming operations which reduces weld lines, material waste, factors of safety, weight, and rework required in an assembly due to formed parts being closer to the final desired shape. Also the resulting mechanical properties can be stronger as can be observed by an increase in stiffness and the surface finish can be of higher quality because fluids will not scratch materials during forming. Singh et al. experimented with different pre-bulging pressures and showed the average roughness value in a hydroformed sample to decrease from 1.84 to $0.96 \mu \mathrm{m}$ in the optimum parameters found [164].

Table 2 Advantages and disadvantages of hydroforming

\begin{tabular}{|c|c|}
\hline Advantages & Disadvantages \\
\hline $\begin{array}{l}\text { - More formability achievable than traditional cold forming [3] } \\
\text { - If cold hydroforming is used there is more strain hardening } \\
\text { than with a warm or hot forming process [81] }\end{array}$ & - Higher initial capital investment for press $(\approx 30 \%)[4]$ \\
\hline $\begin{array}{l}\text { Lower tooling costs with cavity hydroforming than stamping } \\
\text { because of the use of } 1 \text { tool instead of } 2[20]\end{array}$ & $\begin{array}{l}\text { - Higher cycle time than pressing (roughly } 30-60 \text { s } \\
\text { instead of a few seconds) [28] }\end{array}$ \\
\hline $\begin{array}{l}\text { - Occasionally with tube hydroforming, geometries can be created } \\
\text { which would not be possible with other manufacturing methods [4] } \\
\text { - Improved surface finish [164] } \\
\text { - More complex geometry creation in a single operation [7] }\end{array}$ & $\begin{array}{l}\text { - Sharp radii can be difficult to achieve without } \\
\text { pressure intensifiers [166] }\end{array}$ \\
\hline - Reduction of weld lines in an assembly (due to more complicated part formation) [4] & - Potential loss of ductility due to strain hardening [81] \\
\hline $\begin{array}{l}\text { - Reduced required factors of safety if weld lines can be removed [165] } \\
\text { - Weight reduction in an assembly due to removal of nuts, bolts, \& other fasteners [7] } \\
\text { - Less waste due to more representative geometries (nearer to net shape) [4] } \\
\text { - Fewer pressing operations required for complicated components [4] }\end{array}$ & \\
\hline
\end{tabular}


Tooling costs can also be lower than stamping operations as only one tool is required because the other is replaced with fluid pressure.

The major disadvantage with the hydroforming process is the increased costs which express themselves in two distinct ways. First the initial capital investment for equipment is roughly 30\% higher [4] and second, the cycle times for the presses are much longer than conventional cold forming methods. Typical cycle times are around 20 to $60 \mathrm{~s}$ instead of just a few seconds in a traditional cold forming operation [28]. This is because it takes more time to flood and increase fluid pressure inside a chamber than it does to mechanically press a set of dies together. The other disadvantages to a hydroforming process are that it is difficult to produce sharp radii without using pressure intensifiers and that the material loses ductility in the forming process. Required pressure and the smallest radius on a part have an inversely proportional relationship. This means that a radius of $1 \mathrm{~mm}$ takes 4 times as much pressure to form as a radius of $4 \mathrm{~mm}$ so a pressure intensifier is often required to sharpen radii in a secondary operation. Lastly, all forming processes work harden materials which has the effect of stiffening them and reducing their ductility, so if a certain amount of flexibility is required in a hydroformed component a heat treatment might be required post forming. A general set of advantages and disadvantages for all of the hydroforming processes is stated in Table 2.

To understand if a hydroforming process is viable to a specific application, the costs and design benefits of the entire manufacturing process (including all periphery operations) should be weighed against the costs and benefits of the likely alternative manufacturing processes. Bell et al. [7] suggest a methodology which is proven through two case studies for weighing up the benefits of hydroforming as compared to an alternate manufacturing process. While this can vary greatly based upon application, the methodology proposed in the text counts the number and characterizes the complexity of the constituent manufacturing operations and uses this information along with the manufacturing cost to compare the potential manufacturing methods.

Enhanced mechanical properties are difficult to realize from a design perspective and come at the cost of decreased ductility. The degree of strain hardening achieved depends on the details of the specific part geometry and the deformation that will be required to create that geometry. While strain hardening is achievable in a simple one stage process, complications arise with a multi-stage process. Strain hardening occurs in direct proportion to plastic deformation and just like residual stresses, is alleviated with heat treatments. Also strain hardening is not uniform throughout the component and is higher in the places where the most plastic deformation has occurred. It is also important to note that locations with the greatest amounts of strain hardening are often the places where the material thinning is the highest, this is analogous to a uniaxial tensile test where most of the necking takes place next to the fracture.

With regard to how strain hardening affects the design stage of a component, this yields 3 main points:

1) Only the plastic deformation that occurs between the final annealing stage and the final part creation matters in terms of the mechanical properties of the final geometry.

2) Strain hardening comes at the expense of ductility.

3) Strain hardening will be variable throughout the component so no particular overall value can be assumed and the values of the thinnest/weakest places must be considered.

Most of the parts that are made with a hydroforming process can be created either with an alternate forming process or with a patchwork fabrication, and with regard to "advantages/ disadvantages" this is what the hydroforming method should be compared against. A patchwork fabrication is a component that is an assembly of several smaller components all of which are cut, shaped, and welded together to make an assembly. [7]

\section{Hydroforming in the marketplace}

The different hydroforming subcategories all fit into different places in the market based upon the limitations of the individual technologies and the alternate manufacturing methods available. Tube hydroforming operations are suited for complicated cross-sectional geometries and internal shapes. Tube hydroforming produces high value parts, but unlike sheet hydroforming, it uses two dies. This means the tooling cost savings of sheet hydroforming (that benefit low part count) do not apply. Tube hydroforming provides "weight reduction through more efficient section design" [2] so it is beneficial when parts have a particularly high need to be light, such as in the automotive or aerospace sectors, or are rotating as reducing weight reduces the moment of inertia, and the energy required to spin a component. In specific cases the tube hydroforming process is the only method which can form certain geometries in one piece due to the unique way in which fluid acts from the inside while new material is simultaneously fed in, so the future of hydroforming will undoubtedly utilize this advantage.

Sheet hydroforming operations are suited for high value or low part count operations where traditional stamping operations are ineffective and are especially valuable when high surface finishes are required. Because the two main alternative processes (pressing and deep drawing) are generally cheaper in large quantities [20], a clear advantage to hydroforming must present for viability at large volumes. Sheet hydroforming can become advantageous if complicated shapes or high surface quality are required, especially in cases 
where the removal of weld lines or lowering of part count can be achieved [7].

Lastly, shell hydroforming is applicable in low part count manufacturing as it is a labor intensive process. It must be used on geometries manufactured with a simple bulging operation and because dies are not used, the addition of any complicated geometries is not possible. The main advantage of shell hydroforming is that large geometries are possible and it consolidates a lot of smaller individual forming operations into one larger operation. Equally, individually pressing large sheets may necessitate large presses and dies which can be avoided with the shell hydroforming technique.

While all of these criteria in each subcategory do not necessarily need to be present to choose hydroforming, they greatly help the economic justification for using the technology. These market areas just discussed can be seen in Fig. 48.

\section{The future of hydroforming}

Looking at the history of hydroforming, its current uses, the market niches it currently fills, the current research areas and the trajectory of the current competing manufacturing processes, a projection of the future applications of hydroforming technology can be made. This section will briefly go over what the current market niches are, how they will change in the future, and what future applications of tube, sheet, and shell hydroforming might look like.

Although the excitement around hydroforming has worn off in the past decade as the additional costs, cycle times and limitations of the process have become better understood, high value manufacturing sectors will most likely continue to use sheet hydroforming technology in high value applications instead of conventional pressing technology. This is because the additional formability allows for less thinning and more precise geometry creation, and the fluid pressure allows for higher quality surface conditions. The development of technologies like warm hydroforming, impulsive hydroforming, and hydro-rim deep drawing will yield further formability in an operation. This will allow for hydroforming to create geometries with even more elaborate features and deeper draws and possibly manufacture parts currently made by superplastic or creep forming. In cases of high value components, especially when great benefits can be realized with deeper draws and fewer weld lines, sheet hydroforming operations will provide a distinct advantage over other manufacturing processes and this can be seen with the recent interest in the hot gas hydroforming of automotive components [23].

In lower value components, parts that are manufactured with a sheet hydroforming operation need an economic justification because of the additional costs and cycle times imposed by the process. However, both conventional pressing and hydroforming are being automated to greater extents and cycle times for both are decreasing. The good news from a hydroforming perspective is that there are likely greater opportunities for optimization in hydroforming operations as equipment has generally not been automated to the same extent and therefore there is more to be gained through process automation. One manufacturer implemented automation techniques on their hydroforming presses by using sheet metal feeding from coiled sheets and this brought hydroforming cycle times down from $20 \mathrm{~s}$ to $8 \mathrm{~s}$. They also formed two components in one forming operation bringing the effective cycle time down to $4 \mathrm{~s}$. For comparison, several press manufacturers including AIDA [167] and Schuler [98] are currently researching better automation methods for sheet metal pressing which use transfer presses that tightly use the same space. While automation makes both conventional and hydroforming processes more efficient, cycle times in hydroforming are longer and more prohibitive, so the impact of automation is more noticeable.

Tube hydroforming press sales have plateaued in the last decade and estimations of another major increase in hydroforming equipment sales [18] has yet to materialize. There are however many applications for tube hydroforming

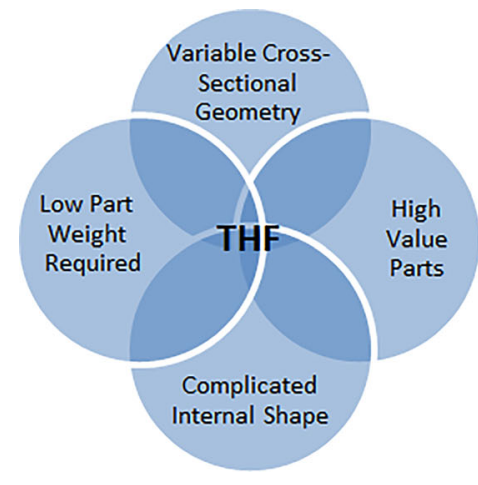

a) Tube hydroforming (THF)

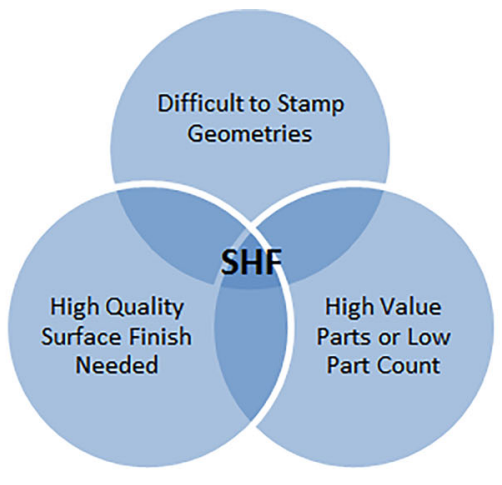

b) Sheet hydroforming (SHF)

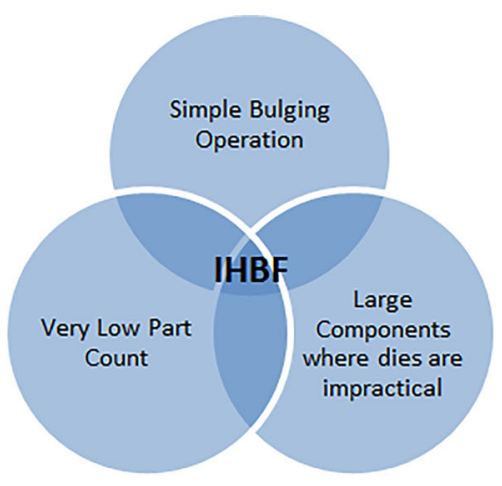

c) Shell hydroforming (IHBF)

Fig. 48 Market areas where hydroforming Subcategories Fit 
Fig. 49 Hydroforming gasturbine engine potential; Courtesy of Rolls-Royce (@Rolls-Royce 2018)



that look promising, specifically in the manufacture of high value and weight sensitive components. For example Zhang et al., [168] show a simulation of an eccentric shaft-like piece which was simulated using moveable-die tooling and suggests that eccentric pieces could be used to a greater extent for crankshafts, camshafts and other rotating parts to reduce weight. This has been suggested as a research area in other previous publications [10] and even patented as far back as 1959 [169], but large scale commercial application has previously been elusive most likely due to problems with achieving industrial part quality for such a technically demanding application. Now that process capability and simulation have increased demanding applications like rotating components are more likely to become viable.

Furthermore, there are many possibilities for the utilization of hydroforming in the aerospace industry as parts are high value, relatively low volume (when compared to the automotive industry) and weight sensitive [7]. Specifically, in the manufacture of gas-turbine engine components, various complicated ductwork pieces such as bleed valve ducts, fairings and complex exhausts could potentially be made with a hydroforming process instead of patchwork fabrications. These examples can be seen in Fig. 49.

As the capability of hydroforming increases due to the ongoing research by many different groups worldwide (as summarized in Table 1) hydroforming will be considered as a manufacturing process for an increasing number of components. The taxonomy developed in Fig. 46 provides a snapshot of what technologies are currently available under the hydroforming umbrella. This allows equipment to be properly sourced where available and identified where still in development. In this way the taxonomy enables hydroforming technology by identifying key current hydroforming technologies which are ready for manufacturing and (along with Fig. 47, the roadmap to future hydroforming technologies) shows which new technologies will likely be available in the future provided they receive adequate research. These new technologies will enable the manufacture of increasingly complicated components like the ones highlighted in Fig. 49.

\section{Conclusion}

This paper summarizes and discusses the past, present, and likely future of hydroforming through the use of academic papers, conference proceedings, books, patents, manufacturer websites, and communication with industrial experts. The first aim of this paper was to provide a comprehensive overview of the state of the art in all forms of hydroforming which was covered in sections 4 and 5 with descriptions of the materials and novel hydroforming techniques. The second aim was to identify emerging hydroforming technologies which was reported in section 6 with a discussion of the recent research and technological developments of hydroforming. The taxonomy shown in Fig. 46 shows all of the recent research and previous technologies in a single hierarchy which was the third aim of this contribution. Then, all of the technologies were assigned a "technology readiness level" of 1-9 in section 6 which was derived from what the academic literature was able to state about each technology fulfilling the 4th aim of this paper. And finally, the 5th aim was characterizing the position of hydroforming with regard to manufacturing and state the likely future. This was done by looking at all of the different 
techniques currently available with hydroforming operations and comparing them with their competing manufacturing processes allowing for the generation of a comprehensive set of advantages and disadvantages and creating a roadmap based upon the upcoming research. Through the careful examination of what the state of the art techniques currently are, the advantages/disadvantages of the technology, and the research that is currently being pursued, a qualified estimation can be made for what the future of hydroforming will likely be in each of its subcategories. Potential hydroforming applications in high value manufacturing seem numerous and this will increase in magnitude with the implementation of technologies currently in development which will allow for greater material formability and reduced manufacturing cost.

Acknowledgements The authors would like to acknowledge support from the EPSRC (project EP/I015698/1), the AFRC and Rolls-Royce for continued funding and support of this work. Also the authors would like to thank Triform Presses for the photographs of industrial examples, the technological descriptions in sections 5.3.2 and 5.3.6 and Bob Blood for his interview concerning the history of hydroforming. The authors would also like to thank Borit technologies for their information about the automation of their processes and Quintus Technologies for their descriptions and schematics of hydroforming technologies such as in process trimming. Finally, the authors would like to thank FF Fluid Forming for the images provided covering the accuracy of their sheet hydroforming process.

\section{Compliance with ethical standards}

Conflict of interest The authors declare that they have no conflict of interest.

Terminology \& Abbreviations SHF/THF, Sheet/Tube Hydroforming; IHBF, Shell Hydroforming (Integrated Hydrobulge Forming); VPF, Viscous Pressure Forming; FLD, Forming Limit Diagram; FEA/FEM, Finite Element Analysis/ Modelling (computer simulation \& modeling); Hydromechanical Deep Drawing, Sheet hydroforming with a punch; FLC, Forming Limit Curve

Open Access This article is distributed under the terms of the Creative Commons Attribution 4.0 International License (http:// creativecommons.org/licenses/by/4.0/), which permits unrestricted use, distribution, and reproduction in any medium, provided you give appropriate credit to the original author(s) and the source, provide a link to the Creative Commons license, and indicate if changes were made.

\section{References}

1. Zhang S, Wang Z, Xu Y, Wang Z, Zhou L (2004) Recent developments in sheet hydroforming technology. J Mater Process Technol 151:237-241

2. Alaswad A, Benyounis K, Olabi A (2012) Tube hydroforming process: a reference guide. Mater Des 33:328-339

3. Zhang S, Danckert J (1998) Development of hydro-mechanical deep drawing. J Mater Process Technol 83(1-3):14-25

4. Zhang S-H (1999) Developments in hydroforming. J Mater Process Technol 91:236-244
5. Jeswiet J, Geiger M, Engel U, Kleiner M, Schikorra M, Duflou J, Neugebauer R, Bariani P, Bruschi S (2008) Metal forming progress since 2000. CIRP J Manuf Sci Technol 1(1):2-17

6. Koç M (2008) Hydroforming for advanced manufacturing, 1st edn. Woodhead Publishing Limited, Cambridge England

7. C. Bell, J. Corney, D. Savings and J. Storr, 2015 "Assessing the potential benefits of manufacturing gas turbine components by utilizing hydroforming technology. In 13th International Cold Forming Congress; 2nd - 4th September 2015, Glasgow

8. Schmoeckel D, Hielscher C, Huber R, Geiger M (1999) Metal forming of tubes and sheets with liquid and other flexible media. CIRP Ann 48(2):497-513

9. Wang Z, Liu G, Yuan S, Teng B, He Z (2005) Progress in Shell hydroforming. J Mater Process Technol 167(2-3):230-236

10. Koç M, Altan T (2001) An overall review of the tube hydroforming (THF) technology. J Mater Process Technol 108(3):384-393

11. M. Koç, 1999 Development of design guidelines for part, tooling and process in the tube hydroforming technology (doctoral dissertation), Columbus Ohio: The Ohio State University

12. H. Singh, 2003 Fundamentals of Hydroforming, Dearborn, Michigan: Society of Manufacturing Engineers

13. Lang LH, Wang ZR, Kang DC, Yuan SJ, Zhang SH, Danckert J, Nielsen KB (2004) Hydroforming highlights: sheet hydroforming and tube hydroforming. J Mater Process Technol:165-177

14. Lee M-G, Korkolis YP, Kim JH (2015) Recent developments in hydroforming technology. Proc Inst Mech Eng B J Eng Manuf: 572-596

15. Park K (1903) Apparatus for forming serpentine hollow bodies. United States of America Patent US731124A 16:6

16. J. Gray, A. Devereaux and W. Parker 1939 "Apparatus for making wrought metal T's". USA Patent US 2203868 A

17. I. G. Cudini, 1986 "Shaping and forming articles". United States of America patent US 4567743 a

18. P. Freytag, 2014 "The renaissance of hydroforming - European market development, challenges and technical responses from the perspective of a serial manufacturer. In Hydroforming of Sheets Tubes and Profiles, Fellbach

19. P. Freytag and J. Neubert, 2016 "Hydroforming in high-volume production. In New Developments in Sheet Metal Forming Hydroforming of Sheets, Tubes and Profiles, Fellbach

20. S. Olsson, 2016 "Recent Hydroform and Flexform development. In New Developments in Sheet Metal Forming - Hydroforming of Sheets, Tubes and Profiles, Fellbach

21. B. Blood, Interviewee, Hydroforming Process Specialist at Triform, Personal Communication. [Interview]. 14 September 2016

22. Smedgarden Moske`\& Rekreasjonssenter, "Smedgarden Moske` $\&$ Rekreasjonssenter does hydro forming with pressure washer of aluminium gas tank for motorcycle. 2013. [Online]. Available: youtube.com/watch?v=RQE9cJApSgQ. [Accessed 79 2015]

23. Tolazzi M (2010) Hydroforming applications in automotive: a review. Fiat, Springer-Verlag (France), Trento Italy

24. Total Materia, "Hydro-forming process of steel: part two. 273 2017. [online]. Available: http://www.totalmateria.com/page. aspx ?ID $=$ CheckArticle \&site $=k t s \& N M=344$. [Accessed 273 2015]

25. Crouse WH (1955) Automotive chassis and body: construction, operation, and maintenance. McGraw-Hill

26. Maki T, Walter C (2007) Liquid curves, sheet hydroforming helps the sporty solstice stand out. Stamping Journal:20

27. Altan T (2002) Sheet hydroforming in automotive applications. Stamping Journal

28. Ahmetoglu M, Altan T (2000) Tube hydroforming: state-of-theart and future trends. J Mater Process Technol 98(1):25-33 
29. Grüner M, Gnibl T, Merklein M (2014) Blank hydroforming using granular material as medium - investigations on leakage. Procedia Engineering 81

30. K. Grote and E. Antonsson 2009 Springer handbook of mechanical engineering, volume 10 ed., Springer Science \& Business Media

31. Su Y, Yang W, Wang C (2013) Upsetting process analysis and numerical simulation of metal pipe's end. Appl Mech Mater 364:488-492

32. Wang Z, Lu J, Wang Z (1999) Numerical and experimental research of the cold upsetting \pm extruding of tube ${ }^{-}$anges. J Mater Process Technol 110:28-35

33. Saboori M, Gholipour J, Champliaud H, Wanjara P, Gakwaya A, Savoie J (2016) Prediction of burst pressure in multistage tube hydroforming of aerospace alloys. J Eng Gas Turbines Power 138(8)

34. Saboori M, Gholipour J, Champliaud H, Gakwaya A, Wanjara P (2015) Prediction of burst pressure in multistage tube hydroforming of aerospace alloys. In: Proceedings of ASME Turbo expo. Montréal, Turbine Technical Conference and Exposition, p 2015

35. Nikhare C, Weiss M, Hodgson PD (2009) FEA comparison of high and low pressure tube hydroforming of TRIP steel. Comput Mater Sci 47(1):146-152

36. G. Morphy, 1998 "Tube hydroforming: dimensional capability analysis of a high volume automotive. In SAE Conference Proceedings $P$. Soc Automotive Engineers

37. Mohamed M, Carty D, Storr J, Zuelli N, Blackwell P, Savings D (2016) Feasibility study of complex sheet hydroforming process: experimental and modelling. Key Eng Mater 716:685-691

38. Siegert K, Häussermann M, Lösch B, Rieger R (2000) Recent developments in hydroforming technology. J Mater Process Technol 98(2):251-258

39. Bagherzadeh S, Mirnia MJ, Dariani BM (2015) Numerical and experimental investigations of hydro-mechanical deep drawing process of laminated aluminum/steel sheets. J Manuf Process 18: 131-140

40. Quintus Technologies, "Sheet Metal Forming - Quintus Technologies. Quintus Technologies AB, [Online]. Available: http://quintustechnologies.com/metal-forming/. [Accessed 35 2017]

41. Beckwood Corporation, "Triform Line of Specialty Forming Presses. [Online]. Available: http://beckwoodpress.com/triformpresses. [Accessed 96 2017]

42. FF Fluid Forming GmbH, "FF Fluid Forming GmbH | Willkommen bei der Hochdruckblechumformung. FF Fluid Forming, 2010. [Online]. Available: http://www.fluidforming. de/index.php/en. [Accessed 35 2017]

43. Hartl C (2015) Micro-hydroforming. In Micromanufacturing Engineering and Technology. William Andrew, Oxford, pp 323343

44. Hashemi A, Hoseinpour Gollo M, Seyedkashi SH (2015) Process window diagram of conical cups in hydrodynamic deep drawing assisted by radial pressure. Trans Nonferrous Metals Soc China: 3064-3071

45. Intarakumthornchai T, Aue-U-Lan Y, Kesvarakul R, Jirathearanat S (2015) Feasible pressure and axial feed path determination for fuel filler tube hydroforming by genetic algorithm. Proc Inst Mech Eng B J Eng Manuf 229(4):623-630

46. Wang C, Wan M, Meng B, Xu L (2017) Process window calculation and pressure locus optimization in hydroforming of conical box with double concave cavities. Int J Adv Manuf Technol 91(14):847-858

47. Shin SGR, Joo BD, Van Tyne CJ, Moon YH (2014) Enhancing tube hydroformability by reducing the local strain gradient at potential necking sites. J Mech Sci Technol 28(10)
48. Abdessalem AB, El-Hami A (2018) A probabilistic approach for optimising hydroformed structures using local surrogate models to control failures. Int J Mech Sci 96:143-162

49. Huang T, Song X, Liu M (2016) A kriging-based non-probability interval optimization of loading path in T-shape tube hydroforming. Int J Adv Manuf Technol 85(5-8):1615-1631

50. Ge Y, Li X, Lang L-H, Ruan S (2017) An adaptive loading path design method for tube hydroforming using fuzzy logic theory. $\mathrm{J}$ Braz Soc Mech Sci Eng 39(7):2607-2617

51. Brooghani SYA, Khalili K, Shahri SEE, Kang BS (2014) Loading path optimization of a hydroformed part using multilevel response surface method. Int J Adv Manuf Technol 70(5-8):1523-1531

52. Abdessalem AB, El-Hami A (2014) Global sensitivity analysis and multi-objective optimisation of loading path in tube hydroforming process based on metamodelling techniques. Int $\mathrm{J}$ Adv Manuf Technol 71(5-8):753-773

53. Xiang N, Wang Z-j, Yi J, Song H (2017) Controlling of material flow in the quasi-bulk forming of thin-walled corrugated rings through optimization of contact pressure. Int J Adv Manuf Technol 91(5-8):2077-2088

54. Ge Y-L, li X-x, Lang L-H, Ruan S-w (2017) Optimized design of tube hydroforming loading path using multi-objective differential evolution. Int J Adv Manuf Technol 88(1-4):837-846

55. Yossifon S, Tirosh J (1984) On suppression of plastic buckling in hydroforming process. Int J Mech Sci 26.6(8):389-402

56. Ali Ablat M, Qattawi A (2016) Numerical simulation of sheet metal forming: a review. Int J Adv Manuf Technol 89:1235-1250

57. Hashemi A, Hoseinpour-Gollo M, Seyedkashi SH, PourkamaliAnaraki A (2017) A new simulation-based metaheuristic approach in optimization of bilayer composite sheet hydroforming. J Braz Soc Mech Sci Eng 39(10):4011-4020

58. Du K-L, Swamy M (2016) Search and optimization by metaheuristics. Springer, New York City

59. M. Mirzaali, G. H. Liaghat, H. M. Naeini, and K. Shojaee, 2011 "Optimization of Tube Hydroforming Process Using Simulated Annealing Algorithm. in Engineering Procedia

60. Öztürk E, Türköz M, Halkacı HS, Koç M (2017) Determination of optimal loading profiles in hydromechanical deep drawing process using integrated adaptive finite element analysis and fuzzy control approach. Int J Adv Manuf Technol 9-12(88):2443-2459

61. K.-i. Manabe, X. Chen, D. Kobayashi and K. Tada, "Development of in-process fuzzy control system for T-shape tube hydroforming. in Procedia Engineering, Nagoya, 2014

62. Ablat MA, Qattawi A (2017) Numerical simulation of sheet metal forming: a review. Int J Adv Manuf Technol:1235-1250

63. Mackerle J (2004) Finite element analyses and simulations of sheet metal forming processes. Eng Comput 21(8):891-940

64. GOM Optical Measuring Techniques, 2009 "Material properties: determination of process limitations in sheet metal forming forming limit diagram. GOM Optical Measuring Techniques

65. Lang L, Tang D, He Y (2017) Describing tube formability during pulsating hydroforming using forming limit diagrams. The Journal of Strain Analysis for Engineering Design 52(4):249-257

66. Paul SK (2013) Theoretical analysis of strain-and stress-based forming limit diagrams. The Journal of Strain Analysis for Engineering Design 48(3):177-188

67. Koç M (2003) Tribological issues in the tube hydroforming process - selection of a lubricant for robust process conditions for an automotive structural frame part. J Manuf Sci Eng 125(3): 484-492

68. Ngaile G, Jaeger S, Altan T (2004) Lubrication in tube hydroforming (THF): part I. lubrication mechanisms and development of model tests to evaluate lubricants and die coatings in the transition and expansion zones. J Mater Process Technol 146(1):108-115 
69. J. P. Ma and L. F. Yang, 2017 "Measurement methods of friction coefficient for plastic deformation of metals under high strain rate. in Materials science forum, Trans Tech Publications

70. A. Abdelkefi, N. Boudeau, P. Malécot, G. Michel and N. Guermazi, 2015 "On the friction effect on the characteristics of hydroformed tube in a square section die: analytical, numerical and experimental approaches. In Key Engineering Materials, Trans Tech Publications

71. Rudraksha SP, Gawande SH (2017) Optimization of process parameters to study the influence of the friction in tube hydroforming. Journal of Bio-and Tribo-Corrosion 3(4)

72. Wang C, Guo B, Shan D, Zhang M, Bai X (2014) Tribological behaviors in microforming considering microscopically trapped lubricant at contact interface. Int J Adv Manuf Technol 71(912):2083-2090

73. Oh S-I, Jeon B-H, Kim H-Y, Yang J-B (2006) Applications of hydroforming processes to automobile parts. J Mater Process Technol:42-55

74. Palumbo G, Zhang S, Tricarico L, Xu C, Zhou L (2006) Numerical/experimental investigations for enhancing the sheet hydroforming process. Int J Mach Tools Manuf 46(11):12121221

75. Parsa MH, Darbandi P (2008) Experimental and numerical analyses of sheet hydroforming process for production of an automobile body part. J Mater Process Technol:381-390

76. Abedrabbo N, Worswick M, Mayer R, Riemsdijk IV (2009) Optimization methods for the tube hydroforming process applied to advanced high-strength steels with experimental verification. J Mater Process Technol 209(1):110-123

77. Mirzaali M, Seyedkashi S, Liaghat G, Naeini HM, Moon YH (2012) Application of simulated annealing method to pressure and force loading optimization in tube hydroforming process. Int J Mech Sci 55(1):78-84

78. Choi H, Koç M, Ni J (2007) Determination of optimal loading profiles in warm hydroforming of lightweight materials. J Mater Process Technol 190(1-3):230-242

79. Djavanroodi F, Derogar A (2010) Experimental and numerical evaluation of forming limit diagram for Ti6Al4V titanium and Al6061-T6 aluminum alloys sheets. Mater Des 31(10):4866-4875

80. R. Herbertz, H. Hermanns and R. Labs, 2013 "Massivumformung kurz und bündig. Deutsche Massivumformung. Hagen : Industrieverb. Massivumformung, Frankfurt

81. Waters FT (2002) Fundamentals of manufacturing for engineers. Taylor \& Francis, London

82. Lăzărescu L, Comșa D-S, Nicodim I, Ciobanu I, Banabic D (2012) Characterization of plastic behaviour of sheet metals by hydraulic bulge test. Trans Nonferrous Metals Soc China 22: 275-279

83. Vitu L, Boudeau N, Malécot P, Michel G, Buteri A (2017) Evaluation of models for tube material characterization with the tube bulging test in an industrial setting. Int J Mater Form:1-16

84. Abdelkefi A, Malécot P, Boudeau N, Guermazi N, Haddar N (2017) Evaluation of the friction coefficient in tube hydroforming with the "corner filling test" in a square section die. International Journal of Advanced Manufacturing Technology, Vols 88(5-8): 2265-2273

85. Hao S, Klamecki BE, Ramalingam S (1999) Friction measurement apparatus for sheet metal forming. Wear 224(1):1-7

86. BSI British Standards Institute, 2004 Metallic materials - Tube - Drift-expanding test, international standard ISO 8493

87. Yossifon S, Tirosh J (1985) Rupture instability in hydroforming deep-drawing process. Int J Mech Sci 27(9):559-570

88. Wang W, Chen S, Tao K, Gao K, Wei X (2017) Experimental investigation of limit drawing ratio for AZ31Bmagnesium alloy sheet in warm stamping. Int J Adv Manuf Technol 92(1-4):723731
89. C. Bell, C. Dixon, B. Blood, J. Corney, D. Savings, E. Jump and N. Zuelli, "Enabling sheet hydroforming to produce smaller radii on aerospace nickel alloys. Int J Mater Form, no. 1960-6214, 18 October 2018

90. C. Bell, E. Jump, W. Kerr, J. Corney, N. Zuelli and D. Savings, "Correlation between von Mises strain and material thinning in a hydroformed sample of Ti35A aerospace grade titanium. in AIP Conference Proceedings, vol. 1896, no. 1, p. 020029, Dublin, 2017

91. F. Klaas, 1997 "Innovations in high pressure hydroforming. in In Proceedings of 2th International Conference on Innovations in Hydroforming Technology, Columbus Ohio

92. Ahmetoglu M, Sutter K, Li X, Altan T (2000) Tube hydroforming - current research, applications and need for training. J Mater Process Technol 98(2):224-231

93. Cheng DM, Teng BG, Guo B, Yuan S (2009) Thickness distribution of a hydroformed Y-shape tube. Mater Sci Eng A 1(449):3639

94. R. Wesselmann and A. Lückmann, 2016 "High-pressure sheet metal forming of various complex components in a single process cycle. In New Developments in Sheet Metal Forming Hydroforming of Sheets, Tubes and Profiles, Fellbach

95. S. Kobayashi, S.-I. Oh and T. Altan, 1989 Metal forming and the finite-element method, Oxford University Press on Demand

96. Wang Y, Nielsen KB, Lang L, Endelt B (2017) Investigation into bulging-pressing compound forming for sheet metal parts with very small radii. Int J Adv Manuf Technol:1-13

97. Stachowicz F (2008) Estimation of hole-flange ability for deep drawing steel sheets. Archives of Civil and Mechanical Engineering 8(2):167-172

98. J. Früh, 2016 "Efficient. Networked. Innovative. In New Developments in Sheet Metal Forming - Hydroforming of Sheets, Tubes and Profiles, Fellbach

99. Borit NV, "Borit Hydrogate ${ }^{\mathrm{TM}}$ Hydroforming. 2017. [Online]. Available: http://www.borit.be/capabilities/hydrogate-forming. [Accessed 202 2017]

100. Geiger M, Merklein M, Cojutti M (2009) Hydroforming of inhomogeneous sheet pairs with counterpressure. Prod Eng 3(1):17-22

101. Qin Y (2015) Overview of micro-manufacturing. In Micromanufacturing Engineering and Technology. Elsevier Inc, Oxford, pp 1-33

102. Ngaile G, Lowrie J (2014) New micro tube hydroforming system based on floating die assembly concept. Journal of Micro and Nano-Manufacturing 2(4)

103. Ngaile G, Lowrie J (2018) Punch design for floating based microtube hydroforming. J Mater Process Technol 253:168-177

104. Sato H, Manabe K, Ito K, Wei D, Jiang Z (2015) Development of servo-type micro-hydromechanical deep-drawing apparatus and micro deep-drawing experiments of circular cups. J Mater Process Technol 224:233-239

105. Sato H, Manabe K, Furushima T, Wei D, Jiang Z, Alexandrov S On the scale dependence of micro Hydromechanical deep drawing. Key Eng Mater 2017

106. Nakamori T, Shukuno K, Manabe K (2017) In-process controlled Y-shape tube hydroforming with high accurate built-in sensors. Procedia Engineering

107. K.-i. Manabe, H. Sato, K. Itai, M. Vilotic and K. Tada, "Factors influencing the forming characteristics in micro tube hydroforming by ultra high-forming pressure. in Procedia Engineering, Cambridge, 2017

108. Luo L, Wei D, Wang X, Zhou C, Huang Q, Xu J, Wu D, Jiang Z (2017) Effects of hydraulic pressure on wrinkling and earing in micro hydro deep drawing of SUS304 circular cups. Int J Adv Manuf Technol:189-197 
109. Bell C, Tamimi S, Corney J, Savings D (2016) Research directions in hydroforming technology. In AIP Conference Proceedings. Vol. 1769. No. 1. AIP Publishing, Nantes

110. S. Yuan, Z. Tang and G. Liu, 2013 "Simulation and experiment on warm hydroforming of az31 magnesium alloy tube. in International manufacturing science and engineering conference collocated with the 41st north American manufacturing research conference ASME

111. D. Landgrebe and F. Schieck, 2015 "Hot gas forming for advanced tubular automobile components: opportunities and challenges. In ASME 2015 International Manufacturing Science and Engineering Conference, Charlotte

112. Aissa S, Mohamed S, Tarek L (2017) Experimental study of steam hydroforming of aluminum sheet metal. Exp Tech 41(5):525-533

113. Acar D, Türköz M, Gedikli H, Halkacı HS, Cora ÖN (2018) Warm Hydromechanical deep drawing of AA 5754-O and optimization of process parameters. J Eng Mater Technol 140(1)

114. Gao T, Zhang W, Xu M, Wang Z (2017) Finite element analysis and experiment on viscous warm pressure bulging of AZ31B magnesium alloy. Journal of Wuhan University of Technology-Mater 32(3):640-644

115. M. Türköz, D. Acar and M. Dilmeç, 2017 "Investigation on the optimal geometrical parameters for cylindrical cups in warm hydromechanical deep drawing process. In Mechanical and Aerospace Engineering (ICMAE), 2017 8th International Conference on

116. S. Rösel and M. Merklein, "Improving formability due to an enhancement of sealing limits caused by using a smart fluid as active fluid medium for hydroforming. Production Engineering 8, Vols. $1-2$, no. 8, pp. 7-15, 2014

117. Chen H, Hess S, Haeberle J, Sebastian P, Philip B, Güner A, Sperl M, Tekkaya E (2016) Enhanced granular medium-based tube and hollow profile press hardening. CIRP Ann Manuf Technol 65: 273-276

118. P. Ruez and S. Knoll, 2016 "Hydroforming hybrid - affordable hybrid light weight design. In New Developments in Sheet Metal Forming - Hydroforming of Sheets, Tubes and Profiles, Fellbach

119. Mankins JC (2009) Technology readiness assessments: a retrospective. Acta Astronautica 65(9):1216-1223

120. D. Landgrebe, V. Kräusel, A. Rautenstrauch, B. Awiszus and J. M. L. Boll, 2016 "Energy-efficiency and robustness in a hybrid process of hydroforming and polymer injection molding. In Conference on Sustainable Manufacturing, Stellenbosch

121. Takata K, Ohwue T, Saga M, Kikuchi M (2000) Formability of Almg alloy at warm temperature. Mater Sci Forum 331-337

122. T. Maeno, K.-i. Mori and C. Unou, 2014 "Improvement of die filling by prevention of temperature drop in gas forming of aluminium alloy tube using air filled into sealed tube and resistance heating. In 11th International Conference on Technology of Plasticity, Nagoya

123. Türköz M, Halkacı HS, Halkacı M, Dilmeç M, Avcı S, Koç M (2016) Design, fabrication, and experimental validation of a warm hydroforming test system. J Manuf Sci Eng 4(138)

124. Maeno T, Mori K, Adachi K (2013) Gas forming of ultra-high strength steel hollow part using air filled into sealed tube and resistance heating. J Mater Process Technol 214:97-105

125. Mori K, Maeno T, Maki S (2007) Mechanism of improvement of formability in pulsating hydroforming of tubes. Int J Mach Tool Manu 47:978-984

126. Loh-Mousavi M, Bakhshi-Jooybari M, Mori KI, Hyashi K (2008) Improvement of formability in T-shape hydroforming of tubes by pulsating pressure. Proc Inst Mech Eng B J Eng Manuf 222(9): $1139-1146$

127. Wang Z, Liu J, Wang X, Hu Z, Guo B (2004) Viscous pressure forming (VPF): state-of-the-art and future trends. J Mater Process Technol 1(151):80-87
128. Shulkin LB, Posteraro RA, Ahmetoglu MA, Kinzel GL, Altan T (2000) Blank holder force (BHF) control in viscous pressure forming (VPF) of sheet metal. J Mater Process Technol 98(1):716

129. Wang Z-J, Liu Y (2010) Investigation on deformation behavior of sheet metals in viscous pressure bulging based on ESPI. J Mater Process Technol 210(11):1536-1544

130. Gao T, Zhang H, Liu Y, Wang Z (2017) The influence of lengthdiameter ratio in forming area on viscous outer pressure forming and limit diameter reduction. J Braz Soc Mech Sci Eng 39(2):481486

131. Golovashchenko SF, Bessonov NM, Ilinich AM (2011) Two-step method of forming complex shapes from sheet metal. J Mater Process Technol 885(5):875

132. M. Soltanpour, A. Fazli and R. J. Niaraki, "High speed hydroforming and direct quenching: an alternative method for production of hot stamped parts with high productivity. in Procedia Engineering, Cambridge, 2017

133. Maeno T, Morti K, Hori A (2014) Application of load pulsation using servo press to plate forging of stainless steel plates. J Mater Process Technol:1379-1387

134. Y. Xu, S. Zhang, M. Cheng, H. Song and X. Zhang, 2014 "Application of pulsating hydroforming in manufacture of engine cradle of austenitic stainless steels. Nagoya

135. W. Liu, Y. Xu and S. Yuan, 2014 "Effect of pre-bulging on wrinkling of curved surface part by hydromechanical deep drawing. In 11th International Conference on Technology of Plasticity, Nagoya

136. Chen Y, Liu W, Zhang Z, Xu Y, Yuan S (2017) Analysis of wrinkling during sheet hydroforming of curved surface shell considering reverse bulging effect. Int J Mech Sci 120:70-80

137. Y.-M. Hwang and Y.-C. Chen, "Study of compound hydroforming of profiled tubes. in Procedia Engineering, Cambridge, 2017

138. Bach F-W, Kleiner M, Tekkaya AE (2013) Investigation of the complex interactions during impulse forming of tubular parts. Process Machine Interactions:491-511

139. Kleiner M, Hermes M, Weber M, Oliver H, Gershteyn G, Bach FW, Alexander B (2007) Tube expansion by gas detonation. Prod Eng 1

140. Thiruvarudchelvan S, Travis F (2003) Hydraulic-pressureenhanced cup-drawing processes - an appraisal. J Mater Process Technol 140:70-75

141. Tirosh J, Shirizly A, Ben-David D, Stanger S (2000) Hydro-rim deep-drawing processes of hardening and rate-sensitive materials. Int J Mech Sci 42:1049-1067

142. Khademi M, Gorji A, Bakhshi M, Yazdi MS (2017) Investigation of wrinkling in hydrodynamic deep drawing assisted by radial pressure with inward flowing liquid. In: Procedia engineering, Palermo, Italy

143. Wang Z-j, Wang P-y, Song H (2014) Research on sheet-metal flexible-die forming using a magnetorheological fluid. J Mater Process Technol 214(11):2200-2211

144. Rösel S, Merklein M (2011) Flow behaviour of magnetorheological fluids, considering the challenge of sealing in blank hydroforming in the flange area with rectangular leakage area cross-sections. Key Eng Mater 473:121-129

145. Merklein M, Rösel S (2010) Characterization of a magnetorheological fluid with respect to its suitability for hydroforming. Int J Mater Form 3:283-286

146. Wang Z-j, Xiang N, Wang P-y, Li Z-x (2017) Property-adjustable forming medium induced extension of sheet metal formability under variable magnetic field. J Mater Process Technol:420-432

147. Merklein MGM (2009) Mechanical behaviour of ceramic beads used as medium for hydroforming at elevated temperatures. Key Eng Mater (410):61-68 
148. Grüner M, Merklein M (2011) Consideration of elastic tool deformation in numerical simulation of hydroforming with granular material used as a medium. Key Eng Mater 473:707-714

149. H. Faraji and K. Khalili, 2015 "New method of cold forming by the spheres for pipe converting to the T-shape tube. in Procedia Technology

150. S. W. Wagner, K. Ng, W. J. Emblom and J. A. Camelio, 2011 "Influence of continuous direct current on the micro tube hydroforming process. in ASME 2011 international manufacturing science and engineering conference ASME

151. Je G, Malka D, Kim H, Hong S, Shin B (2017) A study on micro hydroforming using shock wave of $355 \mathrm{~nm}$ UV-pulsed laser. Appl Surf Sci

152. S. Eftekhari Shahri, S. Y. Ahmadi Boroughani, K. Khalili and B. Kang, 2014 "Ultrasonic tube hydroforming, a new method to improve formability. In 8th International Conference Inter disciplinarity in Engineering, Tirgu-Mures Romania

153. Brandt M e (2016) Laser additive manufacturing: materials, design, Technologies, and applications. Woodhead Publishing

154. Hölker-Jäger R, Tekkaya A (2016) Additive manufacture of tools and dies for metal forming. In: In Laser Additive Manufacturing Materials, Design, Technologies, and Applications. Woodhead Publishing, pp 439-464

155. Kleiner M, Curbach M, Tekkaya AE, Ritter R, Speck K, Trompeter M (2008) Development of ultra high performance concrete dies for sheet metal hydroforming. Prod Eng 2(2):201-208

156. Wang Z-j, Xiang N, Yi J, Song H (2016) Forming thin-walled circular rings with corrugated meridians via quasi-bulk deformation of metal blank and viscous medium. J Mater Process Technol 236:35-47

157. Geiger M, Merklein M, Cojutti M (2007) Integrated tube and double sheet hydroforming technology-optimised process for the production of a complex part. Key Eng Mater 344:477-484

158. Werner M, Psyk V, Albert A, Pröhl M, Kurka P, Landgrebe D, Drossel W-G (2015) New lightweight construction prospects enabled by hydroforming. MATEC Web of Conferences

159. Psyk V, Lieber T, Kurka P, Drossel W-G (2014) Electromagnetic joining of hybrid tubes for hydroforming. In Assembly Technologies and Systems. Procedia CIRP
160. Park JY, Han SW, Jeong HS, Cho JR, Moon YH (2017) Advanced sealing system to prevent leakage in hydroforming. J Mater Process Technol 247:103-110

161. M. Wada, M. Mizumura, K. Iguchi and H. Kaneda, "Large-expansion hydroforming technology achieving three-times expanding. in Procedia Engineering 81, Nagoya, 2014

162. Halkaci HS, Turkoz M, Dilmec M (2014) Enhancing formability in hydromechanical deep drawing processadding a shallow drawbead to the blank holder. J Mater Process Technol 214: $1638-1646$

163. Sato H, Manabe K, Ito K, Wei D, Jiang Z (2015) Development of servo-type micro-hydromechanical deep-drawing apparatus and micro deep-drawing experiments of circular cups. J Mater Process Technol 224:233-239

164. Singh SK, Kumar DR (2008) Effect of process parameters on product surface finish and thickness variation in hydromechanical deep drawing. J Mater Process Technol 204(1-3): 169-178

165. Frith R, Stone M (2015) Weld efficiency factors revisited. Procedia Engineering 130(1):434-445

166. Hwang YM, Lin TC, Chang WC (2007) Experiments on T-shape hydroforming with counter punch. J Mater Process Technol 192193:243-248

167. K. Aida, K. Rothenhagen and A. Papaioanu, 2016 "New developments in servo press technology. In New developments in Sheet Metal Forming - Hydroforming of Sheets, Tubes and Profiles, Fellbach

168. Zhang Q, Shengdun Z, Zhao S (2012) Less loading tubehydroforming technology on eccentric shaft part by using movable die. Mater Trans:820-825

169. G. M. Milton, "Method of making cam shafts. United States of America patent US2892254, 30 June 1959

Publisher's note Springer Nature remains neutral with regard to jurisdictional claims in published maps and institutional affiliations. 